\title{
An Effective Enantioselective Route to the Platensimycin Core
}

\author{
Gojko Lalic and E. J. Corey* \\ Department of Chemistry and Chemical Biology \\ Harvard University, 12 Oxford Street, Cambridge, Massachusetts 02138
}

$\underline{\text { Supplementary Materials }}$

Materials and Methods. Unless stated otherwise, reactions were performed in flame-dried glassware under a positive pressure of nitrogen using freshly distilled dry solvents. Thin-layer chromatography (TLC) was performed using E. Merck silica gel $60 \mathrm{~F}_{254}$ precoated plates $(0.25$ $\mu \mathrm{m})$. Flash chromatography was performed using Baker silica gel (40 $\mu \mathrm{m}$ particle size) and a Biotage SP1. NMR spectra were recorded on Varian Inova-500, or Inova-600 instruments and calibrated using residual undeuterated solvent as an internal reference. IR spectra were recorded on Avatar 360 FTIR spectrometer. Low-resolution and high-resolution mass spectral analyses were performed at the Harvard University Mass Spectrometry Center. Analytical high performance liquid chromatography (HPLC) was performed on an Isco 2350 Series or a Waters 626 HPLC using the indicated chiral column. Commercial grade reagents and solvents were used without further purification except as indicated below. Dichloromethane was distilled from $\mathrm{CaH}_{2}$. Toluene, $\mathrm{Et}_{2} \mathrm{O}$ and THF were purified by Seco Solvent Systems. 

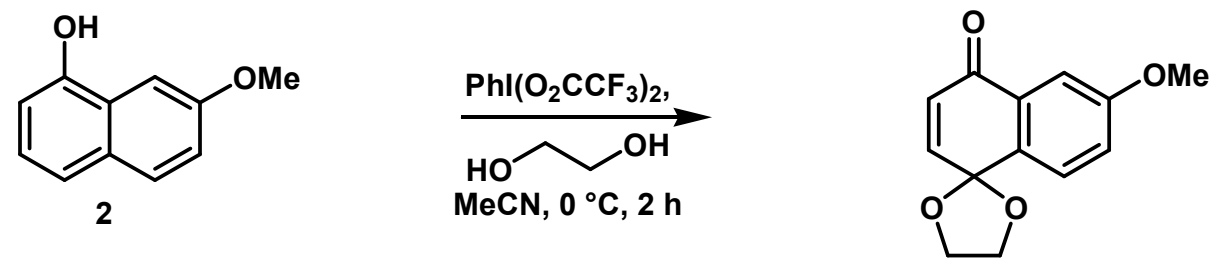

$3,80 \%$

Enone 3: A solution of known phenol $2^{1}$ (7.90 g, 1.00 equiv, $\left.45.3 \mathrm{mmol}\right)$ in $150 \mathrm{~mL}$ of MeCN was added over a two hour period to a solution of $\mathrm{PhI}\left(\mathrm{O}_{2} \mathrm{CCF}_{3}\right)_{2}(42.9 \mathrm{~g}, 2.20$ equiv, 99.6 mmol) in ethyleneglycol $(350 \mathrm{~mL})$ and $\mathrm{MeCN}(100 \mathrm{~mL})$ at $0{ }^{\circ} \mathrm{C}$. After the addition was completed, aq. $\mathrm{NaHCO}_{3}$ was added to the reaction mixture. The product was extracted with ether, and the extract was washed with brine, dried over anhydrous $\mathrm{MgSO}_{4}$, filtered, and concentrated under reduced pressure. The crude product was purified by column chromatography (7\% to $60 \%$ EtOAc in hexane) to yield 3 (7.9 g, 80\% yield) as a yellow amorphous powder; FT-IR (thin film): 2961, 2891, 1670, 1313, 1288, 1108, 1023, $944 \mathrm{~cm}^{-1} ;{ }^{1} \mathrm{H}$ $\operatorname{NMR}\left(500 \mathrm{MHz}, \mathrm{CDCl}_{3}\right): \delta 7.44-7.41(\mathrm{~m}, 2 \mathrm{H}), 7.07\left(\mathrm{dd}, J_{1}=9 \mathrm{~Hz}, J_{2}=3 \mathrm{~Hz}, 1 \mathrm{H}\right), 6.73\left(\mathrm{dd}, J_{1}=\right.$ $\left.10 \mathrm{~Hz}, J_{2}=0.5 \mathrm{~Hz}, 1 \mathrm{H}\right), 6.24\left(\mathrm{dd}, J_{1}=10 \mathrm{~Hz}, J_{2}=0.5 \mathrm{~Hz}, 1 \mathrm{H}\right), 4.27-4.24(\mathrm{~m}, 2 \mathrm{H}), 4.17-4.14(\mathrm{~m}$, 2H), $3.77(\mathrm{~s}, 3 \mathrm{H}) ;{ }^{13} \mathrm{C} \mathrm{NMR}\left(100 \mathrm{MHz}, \mathrm{CDCl}_{3}\right): \delta 184.3,160.7,143.1,133.3,132.4,128.8$, 128.5, 121.5, 108.9, 100.4, 66.0, 55.9; LRMS $\left(\mathrm{ESI}^{+}\right) \mathrm{m} / z$ calc'd $\mathrm{C}_{13} \mathrm{H}_{13} \mathrm{O}_{4}{ }^{+}[\mathrm{M}+\mathrm{H}]^{+}: 233.08$, found 233.08.
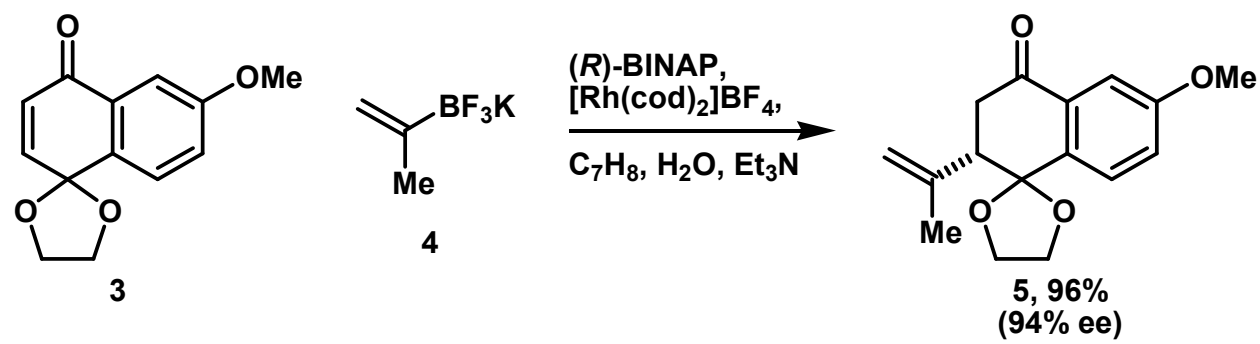

Ketone 5: To a Schlenk tube were added potassium trifluoroborate $4^{2}$ (5.30 g, 2.00 equiv, $36.2 \mathrm{mmol}), 3$ (4.20 g, 1.00 equiv, $18.08 \mathrm{mmol}$ ), (S)-BINAP (0.248 g, 0.022 equiv, $0.398 \mathrm{mmol})$ and $\mathrm{Rh}(\mathrm{cod}){ }_{2} \mathrm{BF}_{4}(0.147 \mathrm{~g}, 0.02$ equiv, $0.362 \mathrm{mmol})$. The tube was evacuated and filled with nitrogen three times. To the mixture was then added $\mathrm{Et}_{3} \mathrm{~N}(10.1 \mathrm{~mL}, 4.00$ equiv, $72.3 \mathrm{mmol})$, followed by toluene $(65 \mathrm{~mL})$ and degassed $\mathrm{H}_{2} \mathrm{O}(16 \mathrm{~mL})$. The Schlenk tube was sealed with a 
teflon stopper and the reaction mixture was stirred at room temperature. After $36 \mathrm{~h}$, the reaction mixture was poured to a mixture of ether and sat. aq. $\mathrm{NH}_{4} \mathrm{Cl}$. The organic layer was washed with brine, dried over $\mathrm{MgSO}_{4}$, filtered and concentrated under reduced pressure. The crude product was purified by silica gel chromatography (4\% to 30\% EtOAc in hexane) to yield product 5 as a colorless oil (4.76 g, 96\% yield, $94 \%$ ee); HPLC (Chiralpac AD column, 3\% $i$-PrOH/hexanes, $\left.1.0 \mathrm{~mL} / \mathrm{min}, 230 \mathrm{~nm}, \mathrm{t}_{\text {major }}=14.8 \mathrm{~min}, \mathrm{t}_{\mathrm{minor}}=11.9 \mathrm{~min} ; \mathrm{ee}=94 \%\right) ;[\alpha]_{\mathrm{D}}{ }^{23}=+8.3(c=1.01$, $\mathrm{CHCl}_{3}$ ); FT-IR (thin film): 3076, 2953, 1683, 1282, 1249, $1031 \mathrm{~cm}^{-1} ;{ }^{1} \mathrm{H}$ NMR (500 MHz, $\left.\mathrm{CDCl}_{3}\right): \delta 7.48-7.45(\mathrm{~m}, 2 \mathrm{H}), 7.13\left(\mathrm{dd}, J_{1}=8 \mathrm{~Hz}, J_{2}=3 \mathrm{~Hz}, 1 \mathrm{H}\right), 4.98-4.97(\mathrm{~m}, 1 \mathrm{H}), 4.84(\mathrm{~s}, 1 \mathrm{H})$, 4.23-4.21 (m, 1H), 4.15-4.02 (m, 3H), $3.84(\mathrm{~s}, 3 \mathrm{H}), 3.11-3.07(\mathrm{~m}, 2 \mathrm{H}), 2.93-2.88(\mathrm{~m}, 1 \mathrm{H}), 1.82(\mathrm{~s}$, $3 \mathrm{H}) ;{ }^{13} \mathrm{C}$ NMR $\left(125 \mathrm{MHz}, \mathrm{CDCl}_{3}\right): \delta 197.4,160.3,143.4,136.5,133.2,126.6,121.8,115.6$, 109.4, 108.1, 66.5, 65.4, 55.8, 50.4, 41.9, 23.6; HRMS $\left(\mathrm{ESI}^{+}\right) \mathrm{m} / z$ calc'd $\mathrm{C}_{16} \mathrm{H}_{19} \mathrm{O}_{4}{ }^{+}[\mathrm{M}+\mathrm{H}]^{+}$: 275.1283 , found 275.1281 .
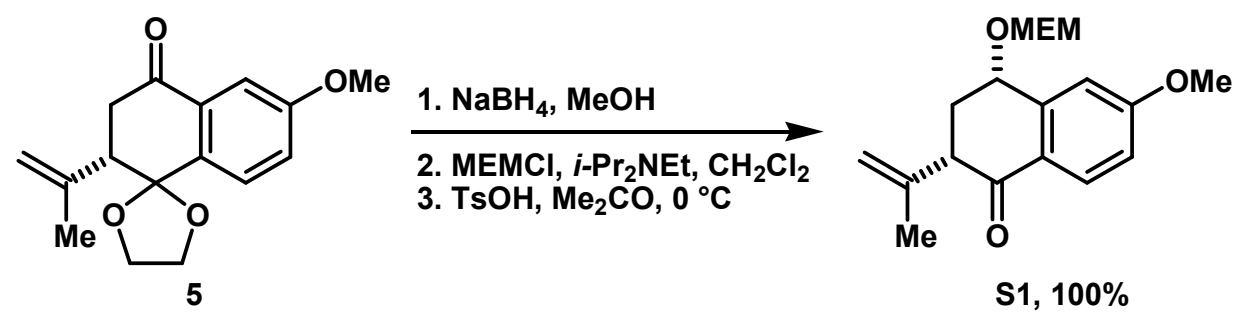

Ketone S1: To a solution of 5 (4.96 g, 1.00 equiv, $18.08 \mathrm{mmol})$ in $\mathrm{MeOH}(50 \mathrm{~mL})$ was added $\mathrm{NaBH}_{4}(0.68 \mathrm{~g}, 1.00$ equiv, $18.08 \mathrm{mmol})$. After $1 \mathrm{~h}$, the reaction mixture was concentrated under reduced pressure. To the residue was added sat. aq. $\mathrm{NH}_{4} \mathrm{Cl}$ solution and the product was extracted with ether. The organic extract was washed with brine, dried over $\mathrm{MgSO}_{4}$, filtered, and concentrated under reduced pressure. The resulting crude alcohol was dissolved in $\mathrm{CH}_{2} \mathrm{Cl}_{2}(60 \mathrm{~mL})$ and was added to a Schlenk tube containing TBAI $(0.67 \mathrm{~g}, 0.10$ equiv, 1.81 mmol). To the resulting solution was added Hünig's base (12.6 mL, 4.00 equiv, $72.3 \mathrm{mmol}$ ), followed by $\mathrm{MEMCl}(4.10 \mathrm{~mL}, 2.00$ equiv, $36.2 \mathrm{mmol})$. The tube was sealed and placed into an oil bath at $80^{\circ} \mathrm{C}$. After $2 \mathrm{~h}$, the reaction mixture was poured in to a separatory funnel containing $0.1 \mathrm{M} \mathrm{HCl}$, and the product was extracted with ether. The organic layer was washed with saturated aq. $\mathrm{NaHCO}_{3}$ and brine, dried over $\mathrm{MgSO}_{4}$, filtered, and concentrated. The crude product was dissolved in acetone $(150 \mathrm{~mL})$ and to the resulting solution was added $\mathrm{p}-\mathrm{TsOH}$ (6.60 g, 1.90 equiv, $34.7 \mathrm{mmol}$ ). The reaction mixture was stirred at room temperature and after 
10 min saturated aq. $\mathrm{NaHCO}_{3}$ was added. Acetone was removed from the reaction mixture under reduced pressure and the product was extracted with ether. The organic extract was washed with brine, dried over $\mathrm{MgSO}_{4}$, filtered, and concentrated under reduced pressure to yield crude ketone S1 in quantitative yield. The crude product was used without further purification in the next step while a small portion of the material was purified by column chromatography to yield ketone $\mathbf{S 1}$ as a white amorphous powder. FT-IR (thin film): 2927, 2877, 1675, 1597, 1237, 1101, $1021 \mathrm{~cm}^{-}$ ${ }^{1}$; ${ }^{1} \mathrm{H}$ NMR $\left(500 \mathrm{MHz}, \mathrm{CDCl}_{3}\right): \delta 8.01(\mathrm{~d}, J=9 \mathrm{~Hz}, 1 \mathrm{H}), 7.12(\mathrm{~d}, J=1.5 \mathrm{~Hz}, 1 \mathrm{H}), 6.88\left(\mathrm{dd}, J_{1}=\right.$ $\left.9 \mathrm{~Hz}, J_{2}=1.5 \mathrm{~Hz}, 1 \mathrm{H}\right), 5.10(\mathrm{~d}, J=7 \mathrm{~Hz}, 1 \mathrm{H}), 5.00-4.97(\mathrm{~m}, 3 \mathrm{H}), 4.87(\mathrm{~s}, 1 \mathrm{H}), 3.88-3.85(\mathrm{~m}, 5 \mathrm{H})$, 3.61-3.60 (m, 2H), $3.39(\mathrm{~s}, 3 \mathrm{H}), 3.21\left(\mathrm{dd}, J_{1}=14 \mathrm{~Hz}, J_{2}=4 \mathrm{~Hz}, 1 \mathrm{H}\right), 2.55-2.52(\mathrm{~m}, 1 \mathrm{H}), 2.22-$ $2.12(\mathrm{~m}, 1 \mathrm{H}), 1.77(\mathrm{~s}, 3 \mathrm{H}) ;{ }^{13} \mathrm{C}$ NMR $\left(100 \mathrm{MHz}, \mathrm{CDCl}_{3}\right): \delta$ 195.6, 164.2, 147.4, 143.5, 130.3, 125.2, 114.8, 114.2, 110.1, 95.1, 74.0, 72.0, 67.8, 59.3, 55.7, 54.5, 36.2, 20.3; HRMS (ESI $\left.{ }^{+}\right) \mathrm{m} / \mathrm{z}$ calc'd $\mathrm{C}_{18} \mathrm{H}_{25} \mathrm{O}_{5}^{+}[\mathrm{M}+\mathrm{H}]^{+}: 321.1696$, found 321.1684 .

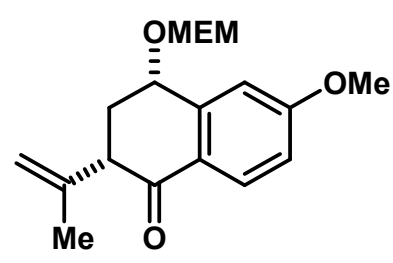

S1

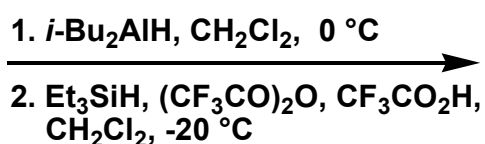
$\mathrm{CH}_{2} \mathrm{Cl}_{2},-20^{\circ} \mathrm{C}$

MEM-Ether 6: To a solution of $\mathbf{S} 1$ (5.80 g, 1.00 equiv, $18.08 \mathrm{mmol})$ in $\mathrm{CH}_{2} \mathrm{Cl}_{2}(120 \mathrm{~mL})$ was added $1 \mathrm{M}$ solution of $i-\mathrm{Bu}_{2} \mathrm{AlH}(36.2 \mathrm{~mL}, 2.00$ equiv, $36.2 \mathrm{mmol})$ in hexane, at $0{ }^{\circ} \mathrm{C}$. The appearance of the reaction mixture during the addition changes from colorless, to yellow, to colorless and the addition was stopped after the first drop that makes the reaction mixture colorless. The reaction was then quenched with a saturated aqueous solution of sodium potassium tartarate $(200 \mathrm{~mL})$ and the biphasic mixture was vigorously stirred for 2 hours at room temperature. The product was extracted from the reaction mixture with ether and the extract was washed with brine, dried over $\mathrm{MgSO}_{4}$, filtered, and concentrated under reduced pressure to yield $5.40 \mathrm{~g}(92 \%$ yield $)$ of the crude alcohol that was used in the following step without further purification.

To a cooled solution $\left(-20^{\circ} \mathrm{C}\right)$ of the alcohol $(5.40 \mathrm{~g}, 1.00$ equiv, $16.8 \mathrm{mmol})$ in $\mathrm{CH}_{2} \mathrm{Cl}_{2}$ (85 $\mathrm{mL}$ ) was added triethylsilane $(21.4 \mathrm{~mL}, 8.00$ equiv, $134 \mathrm{mmol})$, and trifluoroacetic anhydride (3.03 mL, 1.30 equiv, $21.8 \mathrm{mmol})$, followed by a slow addition of trifluoroacetic acid $(0.65 \mathrm{~mL}$, 
0.50 equiv, $8.37 \mathrm{mmol})$. After $3 \mathrm{~h}$ at $-20{ }^{\circ} \mathrm{C}$, the reaction mixture was warmed to $0{ }^{\circ} \mathrm{C}$ and after an additional 0.5 hours sat. aq. $\mathrm{NaHCO}_{3}$ solution was added. The product was extracted from the reaction mixture with ether and the extract was washed with brine, dried over $\mathrm{MgSO}_{4}$, filtered, and concentrated under reduced pressure. The crude product was purified by column chromatography over silica gel (5\% to 30\% EtOAc in hexane) to yield 6 (4.41 g, 86\% yield) as a colorless oil; $[\alpha]_{\mathrm{D}}{ }^{23}=+61.1\left(c=1.20, \mathrm{CHCl}_{3}\right)$; FT-IR (thin film): 2953, 1262, 1104, $1033 \mathrm{~cm}^{-1}$, ${ }^{1} \mathrm{H}$ NMR (500 MHz, $\left.\mathrm{CDCl}_{3}\right): \delta 7.03(\mathrm{~d}, J=3 \mathrm{~Hz}, 1 \mathrm{H}), 7.00(\mathrm{~d}, J=8 \mathrm{~Hz}, 1 \mathrm{H}), 6.76\left(\mathrm{dd}, J_{1}=7 \mathrm{~Hz}\right.$, $\left.J_{2}=3 \mathrm{~Hz}, 1 \mathrm{H}\right), 5.06(\mathrm{~d}, J=7 \mathrm{~Hz}, 1 \mathrm{H}), 4.93(\mathrm{~d}, J=7 \mathrm{~Hz}, 1 \mathrm{H}), 4.85-4.79(\mathrm{~m}, 3 \mathrm{H}), 3.89-3.85(\mathrm{~m}$, $2 \mathrm{H}), 3.84(\mathrm{~s}, 3 \mathrm{H}), 3.62-3.60(\mathrm{~m}, 2 \mathrm{H}), 3.41(\mathrm{~s}, 3 \mathrm{H}), 2.76-2.67(\mathrm{~m}, 2 \mathrm{H}), 2.45-2.40(\mathrm{~m}, 2 \mathrm{H}), 1.80(\mathrm{~s}$, 3H), 1.66-1.61 (m, $1 \mathrm{H}) ;{ }^{13} \mathrm{C} \mathrm{NMR}\left(100 \mathrm{MHz}, \mathrm{CDCl}_{3}\right): \delta 158.3,148.9,138.6,129.9,129.2,113.9$, 111.8, 109.7, 95.0, 76.1, 72.1, 67.5, 59.3, 55.5, 40.8, 35.4, 34.5, 20.8; HRMS (ESI $\left.{ }^{+}\right) \mathrm{m} / z$ calc'd for $\mathrm{C}_{18} \mathrm{H}_{26} \mathrm{KO}_{4}^{+}[\mathrm{M}+\mathrm{K}]^{+}: 345.1468$, found 345.1449 .
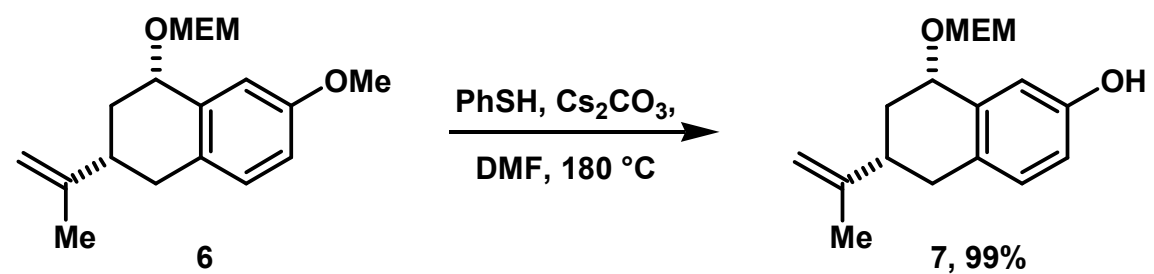

Phenol 7: To a Schlenk tube was added $\mathrm{Cs}_{2} \mathrm{CO}_{3}(5.32 \mathrm{~g}, 2.50$ equiv, $16.3 \mathrm{mmol})$ and 6 (2.00 g, 1.00 equiv, $6.53 \mathrm{mmol})$ as a solution in degassed anhydrous DMF $(25 \mathrm{~mL})$. To the resulting suspension was added thiophenol $(1.34 \mathrm{~mL}, 2.00$ equiv, $13.1 \mathrm{mmol})$, and the reaction mixture was placed in the oil bath preheated to $180{ }^{\circ} \mathrm{C}$. After evolution of $\mathrm{CO}_{2}$ stopped, the tube was sealed with a teflon stopper and the reaction mixture was stirred at the same temperature. After $12 \mathrm{~h}$, the reaction mixture was cooled to room temperature and sat. aq. $\mathrm{NH}_{4} \mathrm{Cl}$ was added. The product was extracted with ether and the organic extract was washed with brine, dried over $\mathrm{MgSO}_{4}$, filtered, and concentrated under reduced pressure. The crude product was purified by column chromatography over silica gel ( $10 \%$ to $50 \%$ EtOAc in Hexane) to yield phenol 7 (1.90 g, $99 \%$ yield) as a colorless oil. $[\alpha]_{\mathrm{D}}^{23}=+60.3\left(c=1.00, \mathrm{CHCl}_{3}\right)$; FT-IR (thin film): 3364 (br), 2922, 2884, 1091, $1033 \mathrm{~cm}^{-1}$; ${ }^{1} \mathrm{H}$ NMR $\left(500 \mathrm{MHz}, \mathrm{CDCl}_{3}\right): \delta 7.03$ (d, $\left.J=2.5 \mathrm{~Hz}, 1 \mathrm{H}\right), 6.94(\mathrm{~d}, J$ $=8.5 \mathrm{~Hz}, 1 \mathrm{H}), 6.68\left(\mathrm{dd}, J_{1}=8.5 \mathrm{~Hz}, J_{2}=2.5 \mathrm{~Hz}, 1 \mathrm{H}\right), 5.60(\mathrm{~s}, 1 \mathrm{H}), 5.03(\mathrm{~d}, J=7.5 \mathrm{~Hz}, 1 \mathrm{H}), 4.90$ $(\mathrm{d}, J=8.5 \mathrm{~Hz}, 1 \mathrm{H}), 4.80-4.78(\mathrm{~m}, 3 \mathrm{H}), 3.95-3.92(\mathrm{~m}, 1 \mathrm{H}), 3.79-3.77(\mathrm{~m}, 1 \mathrm{H}), 3.65-3.63(\mathrm{~m}, 2 \mathrm{H})$, 
$3.49(\mathrm{~s}, 3 \mathrm{H}), 2.78-2.68(\mathrm{~m}, 1 \mathrm{H}), 2.66-2.62(\mathrm{~m}, 1 \mathrm{H}), 2.40-2.37(\mathrm{~m}, 2 \mathrm{H}), 1.79(\mathrm{~s}, 3 \mathrm{H}), 1.63-1.61(\mathrm{~m}$, $1 \mathrm{H}) ;{ }^{13} \mathrm{C}$ NMR $\left(100 \mathrm{MHz}, \mathrm{CDCl}_{3}\right): \delta 154.5,148.9,138.6,130.0,128.9,114.9,113.9,109.7,95.3$, 76.8, 72.3, 67.6, 59.4, 40.9, 35.5, 34.5, 20.8; HRMS $\left(\mathrm{ESI}^{+}\right) \mathrm{m} / \mathrm{z}$ calc'd for $\mathrm{C}_{17} \mathrm{H}_{28} \mathrm{NO}_{4}{ }^{+}$ $\left[\mathrm{M}+\mathrm{NH}_{4}\right]^{+}: 310.2013$, found 310.2023 .
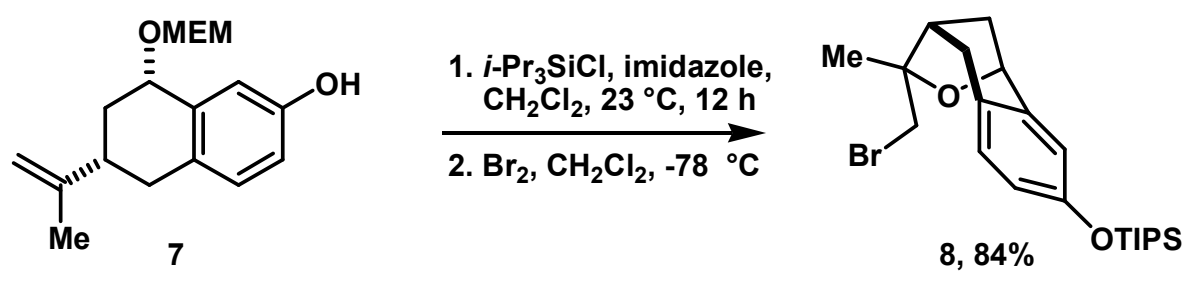

Bromo ether 8: To a solution of $7(1.79 \mathrm{~g}, 1.00$ equiv, $6.13 \mathrm{mmol})$ and imidazole $(0.773 \mathrm{~g}$, 2.00 equiv, 12.3 equiv) in $\mathrm{CH}_{2} \mathrm{Cl}_{2}(15 \mathrm{~mL})$ was added TIPSCl ( $1.44 \mathrm{~mL}, 1.10$ equiv, $\left.6.74 \mathrm{mmol}\right)$ at room temperature. After $16 \mathrm{~h}$, the reaction mixture was diluted with ether and was washed with $0.1 \mathrm{M} \mathrm{HCl}$, sat. aq. $\mathrm{NaHCO}_{3}$, and brine. The organic extract was dried over $\mathrm{MgSO}_{4}$, filtered and concentrated under reduced pressure. The crude reaction product was dissolved in $\mathrm{CH}_{2} \mathrm{Cl}_{2}(60 \mathrm{~mL})$ and to the resulting solution, cooled to $-78{ }^{\circ} \mathrm{C}$, was slowly added a solution of $\mathrm{Br}_{2}$ in $\mathrm{CH}_{2} \mathrm{Cl}_{2}(10 \% \mathrm{v} / \mathrm{v})$. After the addition was completed sat. aq. $\mathrm{Na}_{2} \mathrm{~S}_{2} \mathrm{O}_{3}$ was added and the reaction mixture was warmed to room temperature. The resulting solution was extracted with ether and the organic extract was washed with brine, dried over $\mathrm{MgSO}_{4}$, filtered, and concentrated under reduced pressure. The crude product was purified by column chromatography over silica gel ( $2 \%$ to $12 \%$ EtOAc in hexane) to yield $\mathbf{8}$ as an inseparable mixture of diastereoisomers $(>10: 1)(2.25 \mathrm{~g}, 84 \%$ yield $) .[\alpha]_{\mathrm{D}}^{23}=+113.1\left(c=1.01, \mathrm{CHCl}_{3}\right)$; FTIR (thin film): 2943, 2866, 1272, $880 \mathrm{~cm}^{-1} ;{ }^{1} \mathrm{H}$ NMR (500 MHz, $\left.\mathrm{C}_{6} \mathrm{D}_{6}\right): \delta 6.76-6.77(\mathrm{~m}, 2 \mathrm{H})$, $6.70(\mathrm{t}, J=1.5 \mathrm{~Hz}, 1 \mathrm{H}), 4.59$ (d, $J=4.5 \mathrm{~Hz}, 1 \mathrm{H}), 3.19-3.21(\mathrm{~m}, 2 \mathrm{H}), 3.16(\mathrm{~d}, J=17.5 \mathrm{~Hz}, 1 \mathrm{H})$, $2.66\left(\mathrm{dd}, J_{1}=17.5 \mathrm{~Hz}, J_{2}=4 \mathrm{~Hz}, 1 \mathrm{H}\right), 2.13-2.17(\mathrm{~m}, 1 \mathrm{H}), 2.04-2.11(\mathrm{~m}, 1 \mathrm{H}), 1.55(\mathrm{~d}, J=11.5$ $\mathrm{Hz} 1 \mathrm{H}), 1.34$ (s, 3H), 1.12-1.20 (m, 3H), 1.12-1.04 (m, 18H); $\left.{ }^{13} \mathrm{C} \mathrm{NMR} \mathrm{(100} \mathrm{MHz,} \mathrm{C}_{6} \mathrm{D}_{6}\right): \delta$ 154.4, 142.3, 129.8, 126.7, 119.8, 118.7, 84.2, 78.5, 41.7, 38.6, 35.1, 31.5, 26.3, 18.1, 13.0; HRMS $\left(\mathrm{ESI}^{+}\right) \mathrm{m} / z$ calc'd for $\mathrm{C}_{22} \mathrm{H}_{36} \mathrm{BrO}_{2} \mathrm{Si}^{+}[\mathrm{M}+\mathrm{H}]^{+}: 439.1662$, found 439.1669 . 

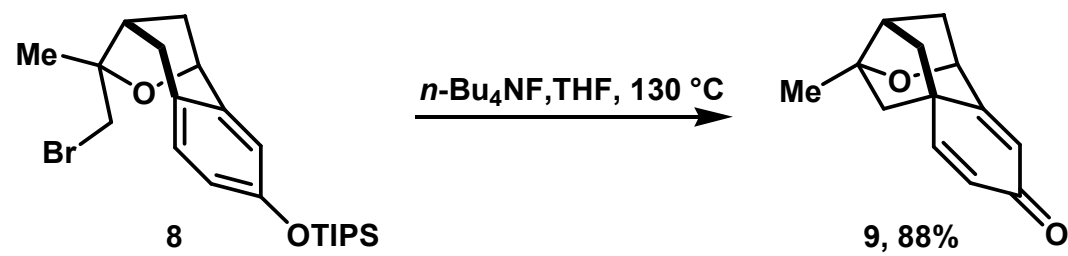

Dienone 9: To a solution of 8 (3.77 g, 1.00 equiv, $8.58 \mathrm{mmol})$ in THF (60 mL) in a Schlenk flask was added $1 \mathrm{M}$ solution of TBAF in THF (10.3 mL, 1.20 equiv, $10.3 \mathrm{mmol})$ at room temperature. The flask was sealed and placed in a $130{ }^{\circ} \mathrm{C}$ oil bath. After $4 \mathrm{~h}$, the reaction mixture was cooled to room temperature, diluted with EtOAc, and washed with sat. aq. $\mathrm{NH}_{4} \mathrm{Cl}$ and brine. The aqueous phase was extracted with EtOAc, and the combined organic extracts were dried over $\mathrm{MgSO}_{4}$, filtered, and concentrated under reduced pressure. The crude product was purified by column chromatography (10\% to $80 \%$ EtOAc in hexane) to yield 9 as a white amorphous powder $(1.53 \mathrm{~g}, 88 \%$ yield $) .[\alpha]_{\mathrm{D}}^{23}=+33.7\left(c=1.25, \mathrm{CHCl}_{3}\right)$; FT-IR (thin film): 2963, 1655, 1626, $1147 \mathrm{~cm}^{-1}$; ${ }^{1} \mathrm{H}$ NMR (500 MHz, $\left.\mathrm{CDCl}_{3}\right): \delta 6.66(\mathrm{~d}, J=10 \mathrm{~Hz}, 1 \mathrm{H}), 6.31$ (dd, $\left.J_{1}=10 \mathrm{~Hz}, J_{2}=2 \mathrm{~Hz}, 1 \mathrm{H}\right), 6.11(\mathrm{~d}, J=10 \mathrm{~Hz}, 1 \mathrm{H}), 4.71(\mathrm{~d}, J=5 \mathrm{~Hz}, 1 \mathrm{H}), 2.58(\mathrm{t}, J=6 \mathrm{~Hz}, 1 \mathrm{H})$, 2.26-2.20 (m, 1H), 2.14-2.19 (m, 1H), 1.92-1.99 (m, 2H), $1.77(\mathrm{~d}, J=11.5 \mathrm{~Hz}, 1 \mathrm{H}), 1.72-1.50$ (m, 4H); ${ }^{13} \mathrm{C}$ NMR (100 MHz, $\left.\mathrm{CDCl}_{3}\right): \delta 187.1,160.4,150.9,130.0,121.8,87.1,80.0,54.8,49.9$, 48.6, 44.4, 42.5, 22.2; LRMS $\left(\mathrm{ESI}^{+}\right) \mathrm{m} / z$ calc'd for $\mathrm{C}_{13} \mathrm{H}_{15} \mathrm{O}_{2}{ }^{+}[\mathrm{M}+\mathrm{H}]^{+}:$: 203.11, found 203.11.
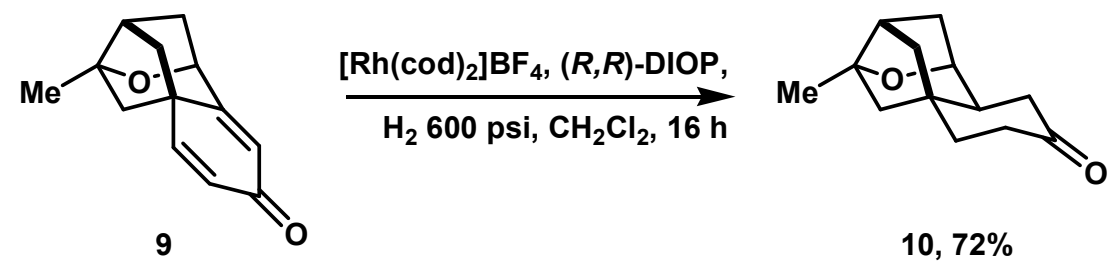

$10,72 \%$

Ketone 10: To a flask containing $9(0.60 \mathrm{~g}, 1.00$ equiv, $2.97 \mathrm{mmol}),\left[\mathrm{Rh}(\mathrm{cod})_{2}\right] \mathrm{BF}_{4}(0.24 \mathrm{~g}$, 0.20 equiv, $0.59 \mathrm{mmol})$ and $(4 R, 5 R)$-DIOP ( $0.30 \mathrm{~g}, 0.20$ equiv, $0.59 \mathrm{mmol})$ was added $\mathrm{CH}_{2} \mathrm{Cl}_{2}$ $(60 \mathrm{~mL})$. The flask was quickly transferred to a hydrogenation apparatus. The hydrogenation apparatus was flushed with hydrogen three times and filled with 600 psi of hydrogen. After $12 \mathrm{~h}$ the reaction mixture was placed under a nitrogen atmosphere and Dess-Martin reagent was added in small portions until all of the alcohol byproduct (less than 0.1 equiv) disappeared. To the resulting reaction mixture was added silica gel $(3 \mathrm{~g})$ and the solvent was removed under reduced pressure. The desired product 10 was obtained after the column chromatography (5\% to 60\% $\mathrm{Et}_{2} \mathrm{O}$ in hexane $)$ as a white amorphous powder $(0.44 \mathrm{~g}, 72 \%$ yield $) . \quad[\alpha]_{\mathrm{D}}^{23}=-10.8(c=0.84$, 
$\mathrm{CHCl}_{3}$ ); FT-IR (thin film): 2944, 1709, $1040 \mathrm{~cm}^{-1} ;{ }^{1} \mathrm{H}$ NMR (500 MHz, $\mathrm{CDCl}_{3}$ ): $\delta 4.07$ (t, $J=10$ $\mathrm{Hz}, 1 \mathrm{H}), 2.40-2.29(\mathrm{~m}, 3 \mathrm{H}), 2.26-2.22(\mathrm{~m}, 2 \mathrm{H}), 2.12-2.02(\mathrm{~m}, 2 \mathrm{H}), 1.90-1.78(\mathrm{~m}, 3 \mathrm{H}), 1.68$ (dd, $\left.J_{1}=11 \mathrm{~Hz}, J_{2}=3 \mathrm{~Hz}, 1 \mathrm{H}\right), 1.65-1.59(\mathrm{~m}, 1 \mathrm{H}), 1.52(\mathrm{~d}, J=11 \mathrm{~Hz}, 1 \mathrm{H}), 1.43-1.40(\mathrm{~m}, 4 \mathrm{H}) ;{ }^{13} \mathrm{C}$ NMR (100 MHz, $\left.\mathrm{CDCl}_{3}\right): \delta 210.6,86.0,79.2,52.6,45.1,44.9,44.3,41.5,39.9,39.2,37.0,35.0$, 23.1; HRMS $\left(\mathrm{ESI}^{+}\right) \mathrm{m} / z$ calc'd for $\mathrm{C}_{13} \mathrm{H}_{19} \mathrm{O}_{2}{ }^{+}[\mathrm{M}+\mathrm{H}]^{+}: 207.1385$, found 207.1380.

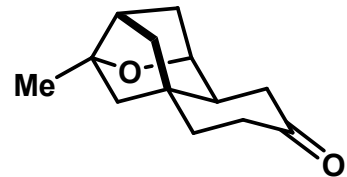

10

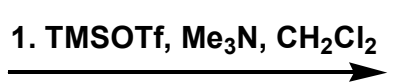

2. IBX, MPO, DMSO

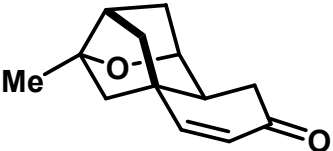

$11,80 \%$

Enone 11: To a solution of 10 (0.054 g, 1.00 equiv, $0.262 \mathrm{mmol})$ and $\mathrm{Me}_{3} \mathrm{~N}(0.15 \mathrm{~mL}, 6.00$ equiv, $1.57 \mathrm{mmol})$ in $\mathrm{CH}_{2} \mathrm{Cl}_{2}(2.6 \mathrm{~mL})$ at $0{ }^{\circ} \mathrm{C}$ was added TMSOTf $(0.14 \mathrm{~mL}, 3.00$ equiv, 0.78 mmol). After $1.5 \mathrm{~h}$ pentane was added and the resulting mixture was extracted with aq. $\mathrm{NaHCO}_{3}$ and brine, dried over $\mathrm{Na}_{2} \mathrm{SO}_{4}$, and concentrated under reduced pressure. The crude product was dissolved in DMSO $(0.10 \mathrm{~mL})$ and $0.4 \mathrm{M}$ solution of IBX and MPO (4-Methoxy pyridine- $N$ oxide) in DMSO (0.98 mL, 1.5 equiv, $0.39 \mathrm{mmol})$ was added at room temperature. After $1.5 \mathrm{~h}$, to the reaction mixture was added sat. aq. $\mathrm{NaHCO}_{3}$ and the resulting solution was extracted with EtOAc. The organic extracts were combined and were extracted with brine, dried over $\mathrm{MgSO}_{4}$, filtered, and concentrated under reduced pressure. The crude product obtained as a 7.2:1 mixture of regioisomers was purified by column chromatography (4\% to 60\% EtOAc in benzene) to yield 11 (0.043 g, 80\% yield, 98\% ee) as a white solid. HPLC (Chiralpac AD-H column, 2\% $i$ $\mathrm{PrOH} / \mathrm{h}$ exanes, $1.0 \mathrm{~mL} / \mathrm{min}, 230 \mathrm{~nm}$, tmajor $=16.3 \mathrm{~min}, \mathrm{t}_{\text {minor }}=18.4 \mathrm{~min}$; ee $\left.=98 \%\right) ;[\alpha]_{\mathrm{D}}{ }^{23}=-$ $16.6\left(c=1.00, \mathrm{CHCl}_{3}\right)$; FT-IR (thin film): 2948, 1674, 1137, 1082, $1036 \mathrm{~cm}^{-1} ;{ }^{1} \mathrm{H}$ NMR $(500$ $\left.\mathrm{MHz}, \mathrm{CDCl}_{3}\right): \delta 6.62(\mathrm{~d}, J=10.0 \mathrm{~Hz}, 1 \mathrm{H}), 5.94(\mathrm{~d}, J=10.0 \mathrm{~Hz}, 1 \mathrm{H}), 4.16\left(\mathrm{dd}, J_{1}=3.4 \mathrm{~Hz}, J_{2}=\right.$ $3.4 \mathrm{~Hz}, 1 \mathrm{H}), 2.44-2.27$ (m, 4H), 1.97-1.92 (m, 2H), 1.89 (d, J=11.5 Hz, 1H), 1.78-1.73 (m, 2H), $1.66(\mathrm{~d}, J=11 \mathrm{~Hz}, 1 \mathrm{H}), 1.44(\mathrm{~s}, 3 \mathrm{H}) ;{ }^{13} \mathrm{C} \mathrm{NMR}\left(120 \mathrm{MHz}, \mathrm{CDCl}_{3}\right): \delta=199.1,155.2,128.9,87.0$, 79.0, 51.7, 46.2, 44.1, 42.7, 42.2, 37.9, 37.5, 23.1; LRMS (ESI $\left.{ }^{+}\right) \mathrm{m} / z$ calc'd for $\mathrm{C}_{13} \mathrm{H}_{17} \mathrm{O}_{2}{ }^{+}$ $[\mathrm{M}+\mathrm{H}]^{+}:$205.12, found 205.12.

\section{References:}

(1) Hulme, A. N.; Henry, S. S.; Meyers, A. I. J. Org. Chem. 1995, 60, 1265-1270. 
(2) Molander, G. A.; Ribagorda, M. J. Org. Chem. 2003, 125, 11148-11149. 


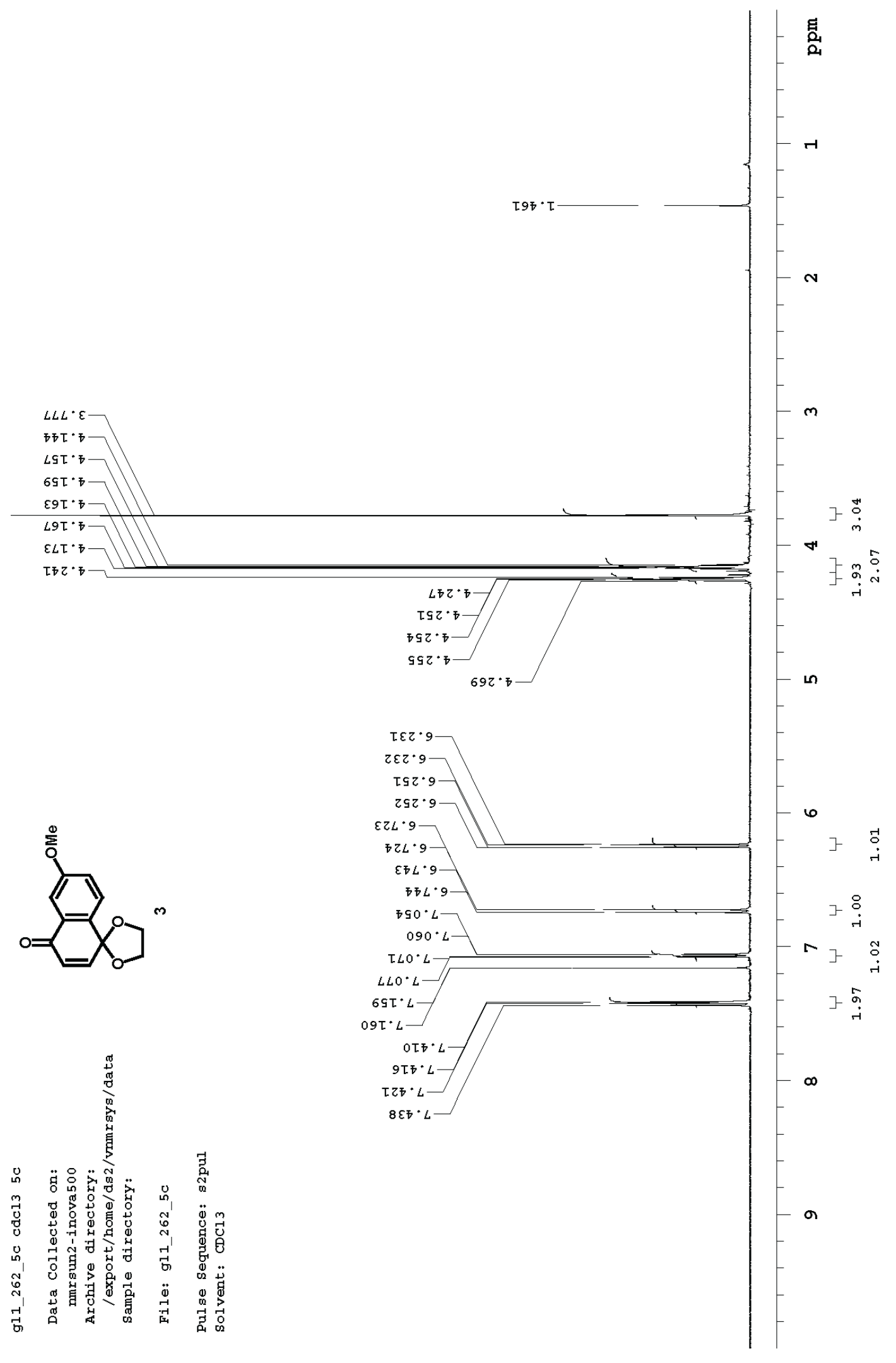




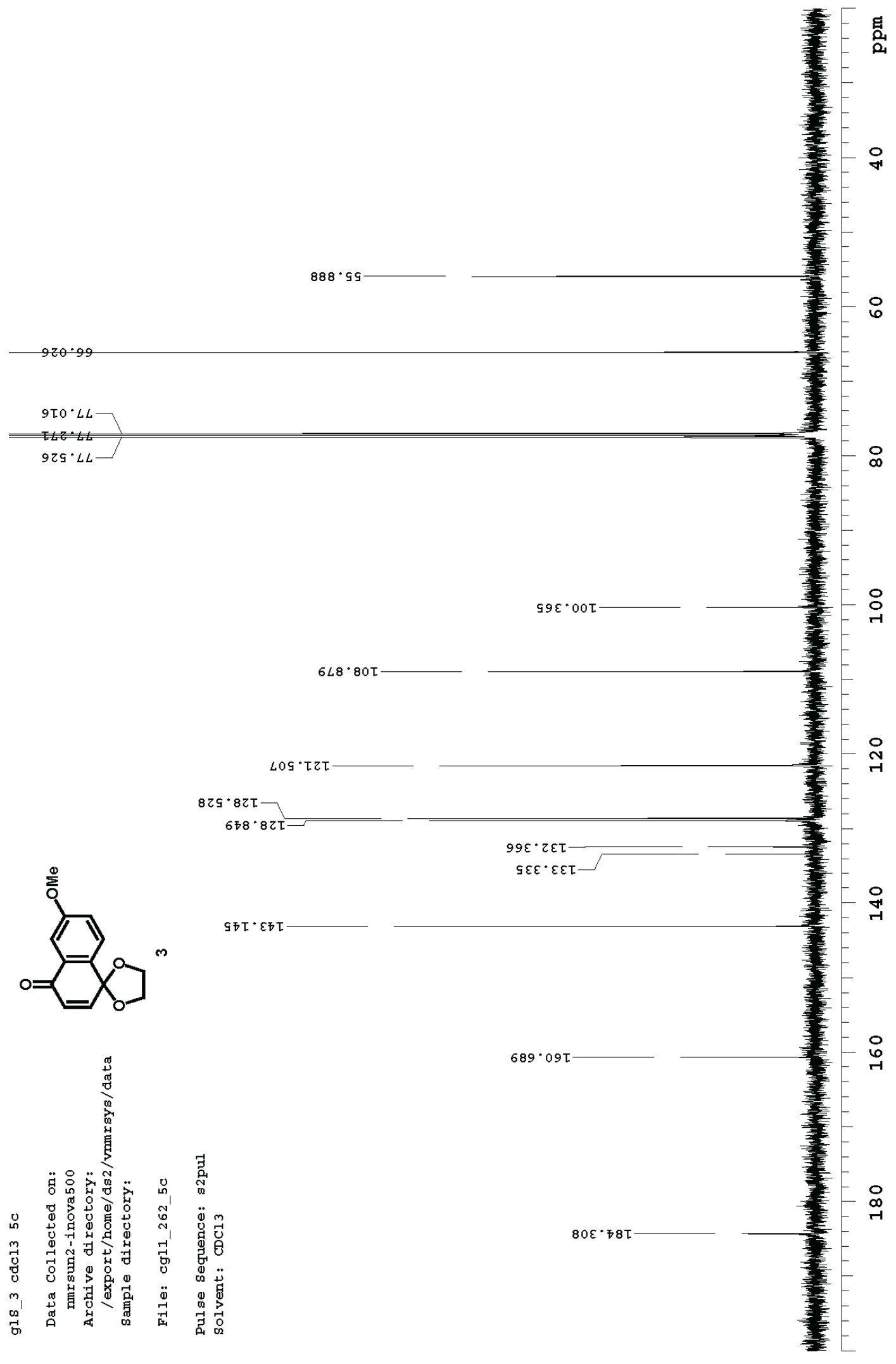




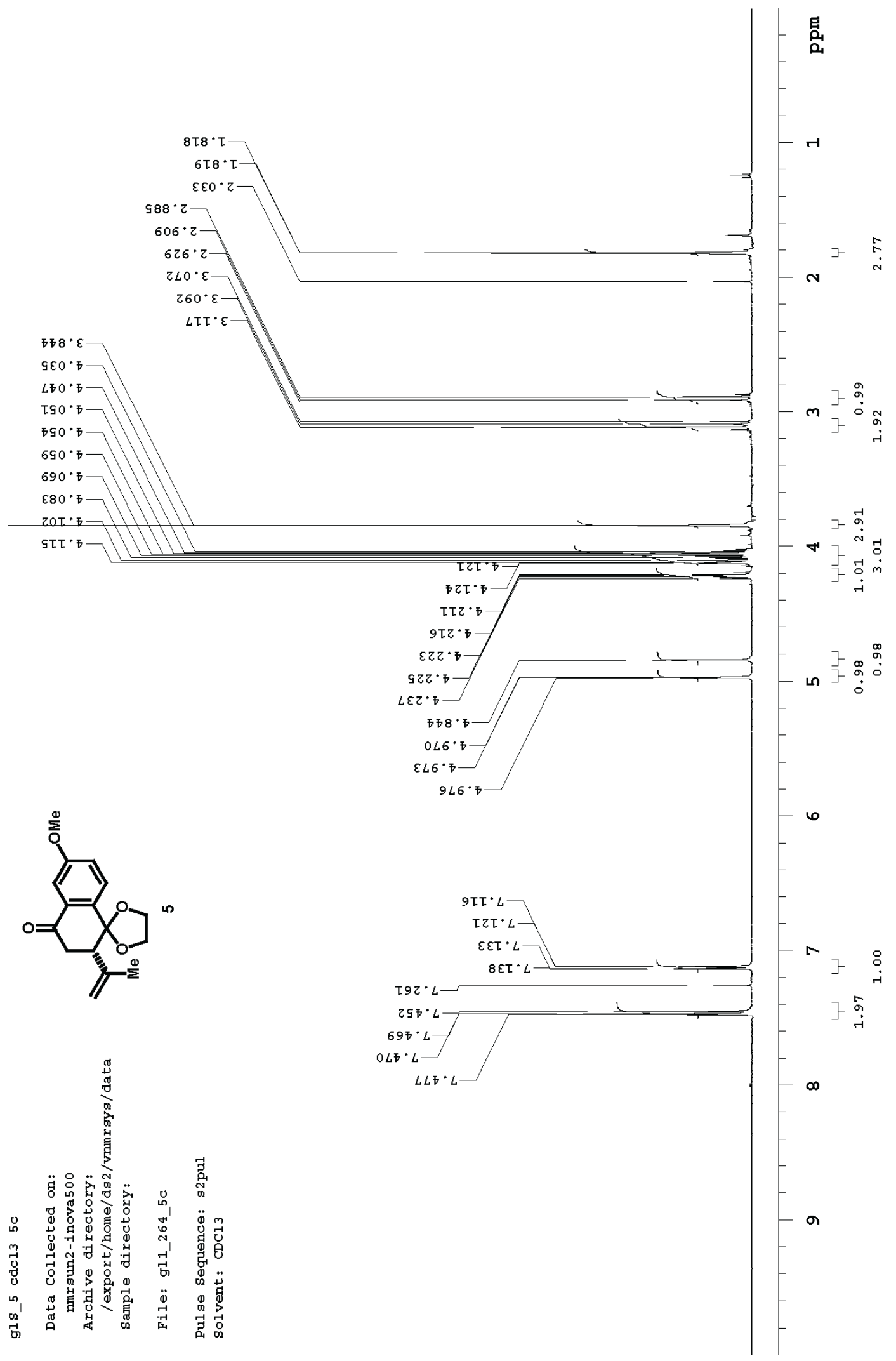




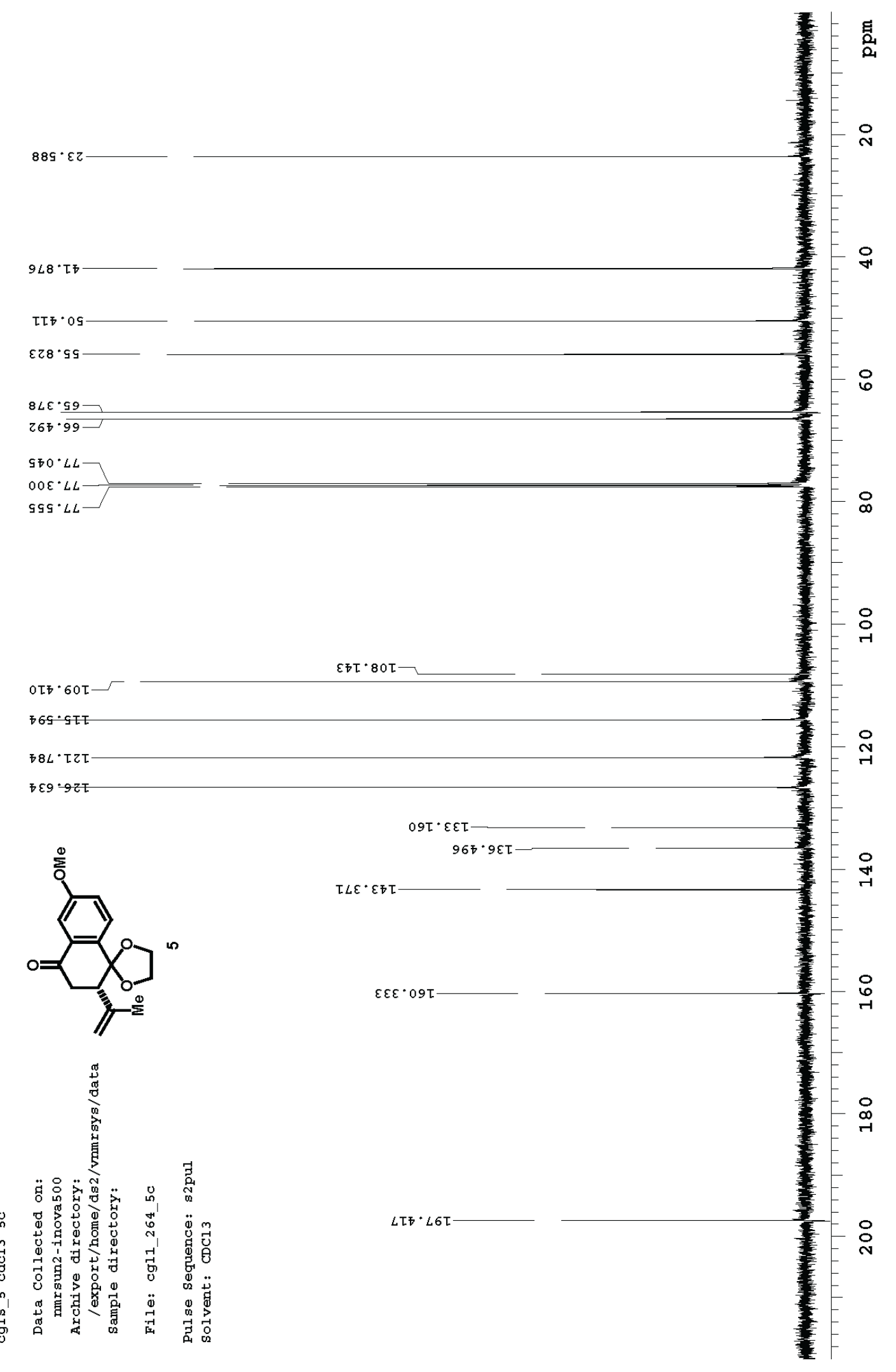



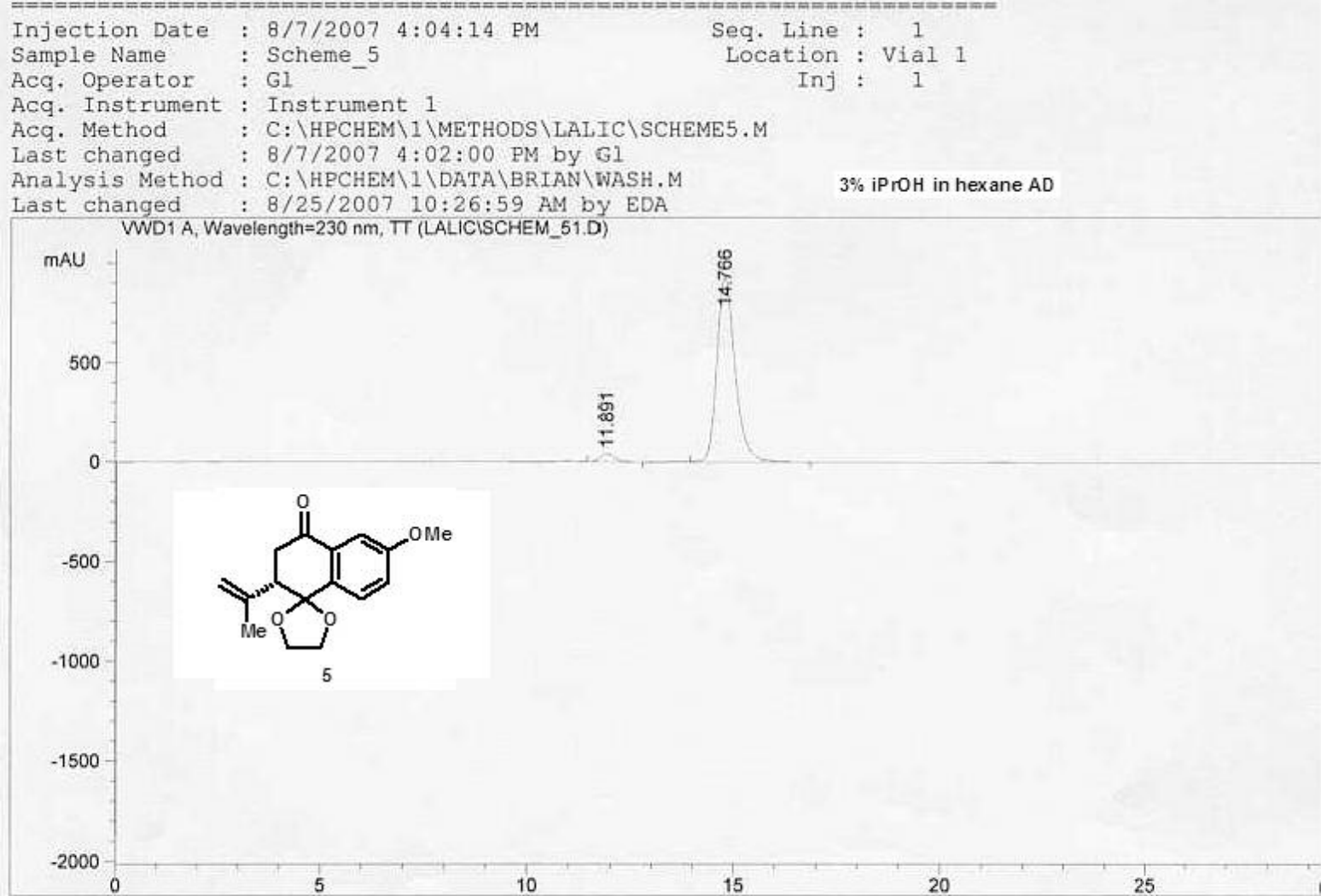

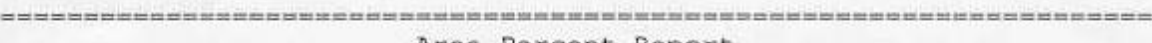

Area Percent Report

\begin{tabular}{|c|c|c|}
\hline Sorted By & : & Signal \\
\hline Multiplier & : & 1.0000 \\
\hline Dilution & : & 1.0000 \\
\hline
\end{tabular}

Use Multiplier \& Dilution Factor with ISTDs

Signal 1: VWD1 A, Wavelength=230 nm, TT

\begin{tabular}{|c|c|c|c|c|c|c|}
\hline $\begin{array}{c}\text { Peak } \\
\#\end{array}$ & $\begin{array}{l}\text { RetTime } \\
\text { [min] }\end{array}$ & Type & $\begin{array}{l}\text { Width } \\
\text { [min] }\end{array}$ & $\begin{array}{l}\text { Area } \\
\mathrm{mAU}{ }^{*}{ }^{2}\end{array}$ & $\begin{array}{l}\text { Height } \\
{[\mathrm{mAU}]}\end{array}$ & $\begin{array}{c}\text { Area } \\
\frac{8}{8}\end{array}$ \\
\hline$\frac{--1}{2}$ & $\begin{array}{l}11.891 \\
14.766\end{array}$ & $\begin{array}{l}\text { VP } \\
\text { VB }\end{array}$ & $\begin{array}{l}0.3536 \\
0.4717\end{array}$ & $\begin{array}{r}988.25433 \\
2.89153 \mathrm{e} 4\end{array}$ & $\begin{array}{r}42.59863 \\
930.59106\end{array}$ & $\begin{array}{r}3.3048 \\
96.6952\end{array}$ \\
\hline Tota. & : & & & $2.99035 \mathrm{e} 4$ & 973.1 & \\
\hline
\end{tabular}

Results obtained with enhanced integrator!

$\star * *$ End of Report *** 


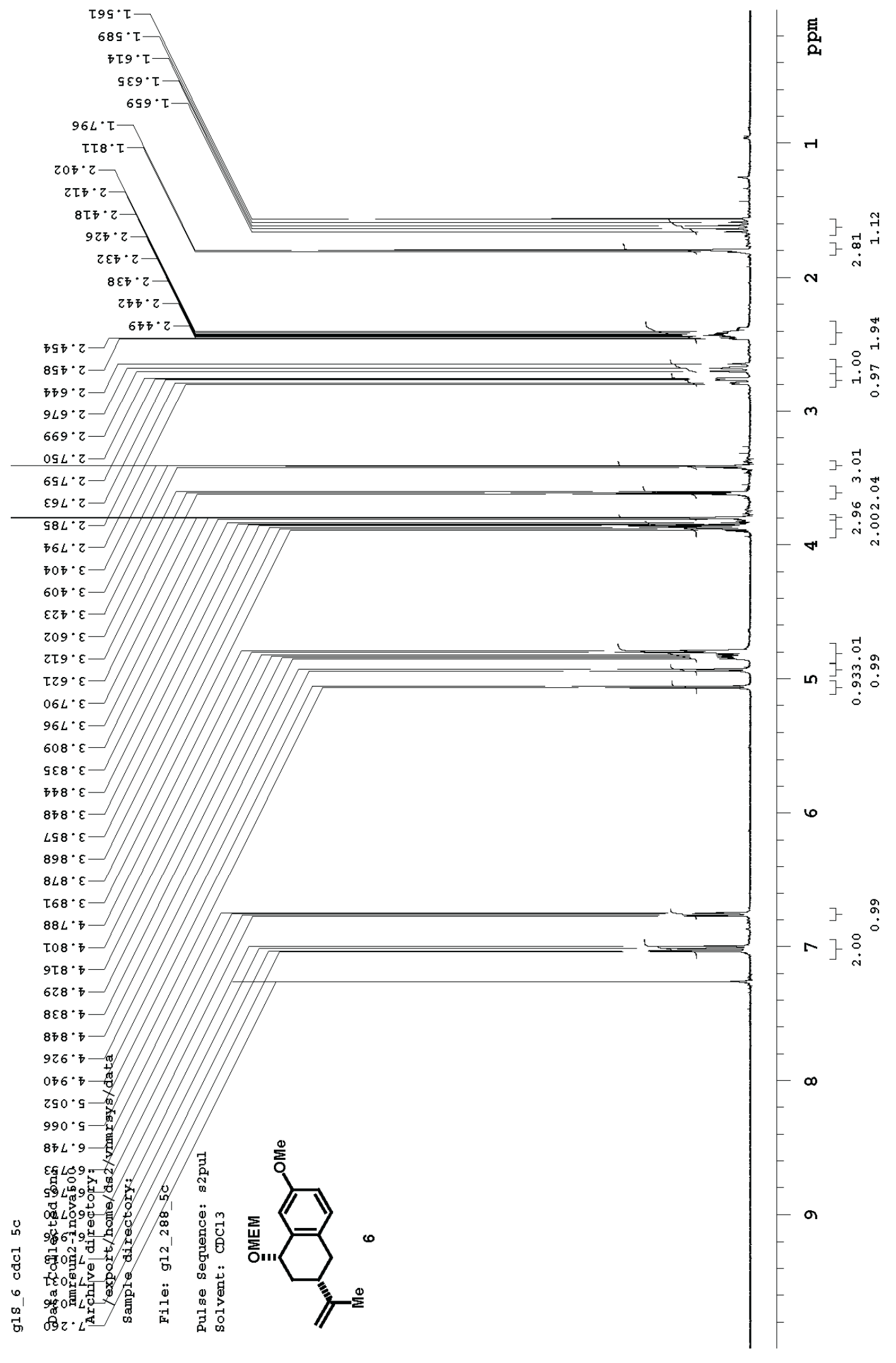




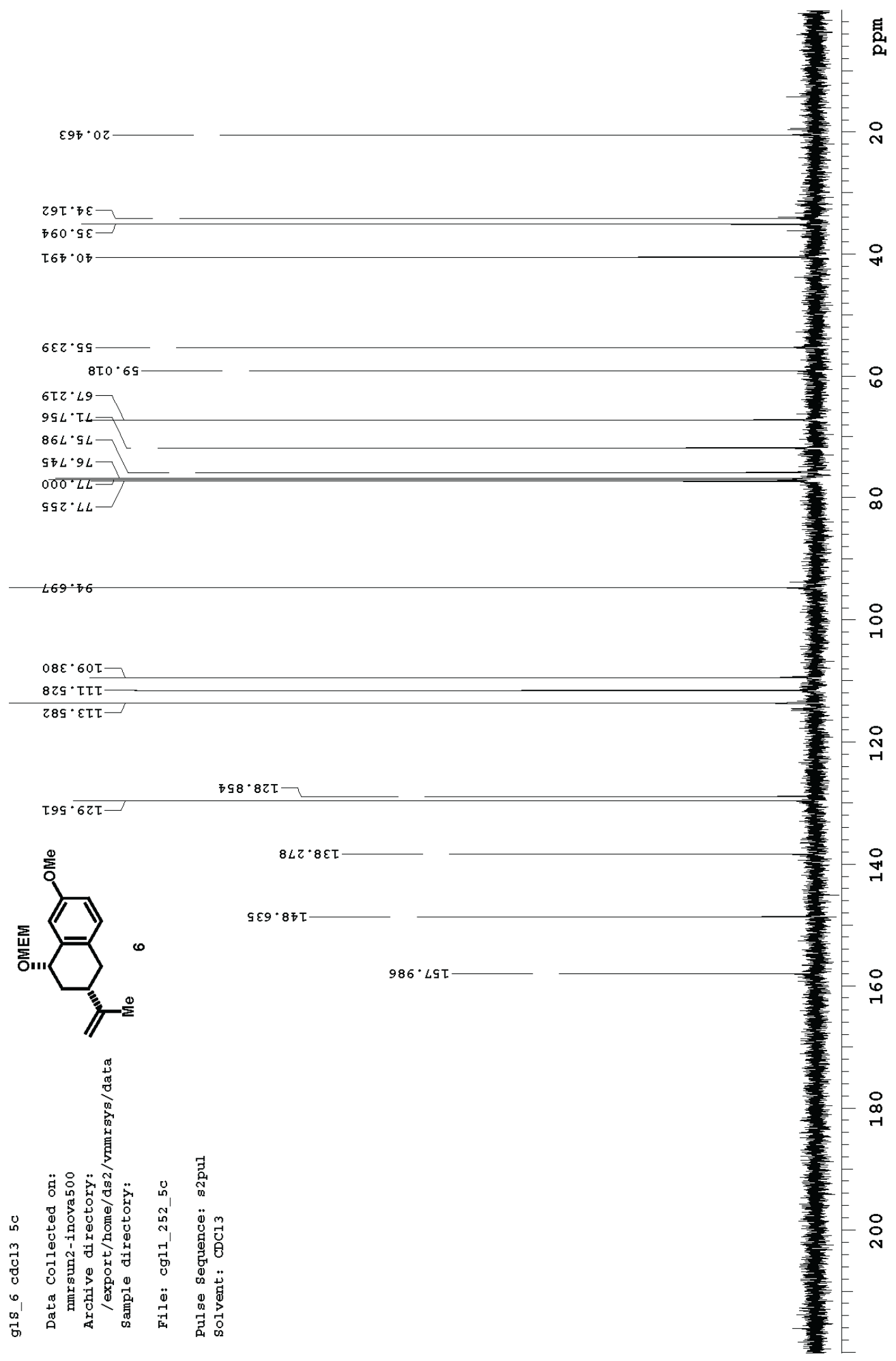




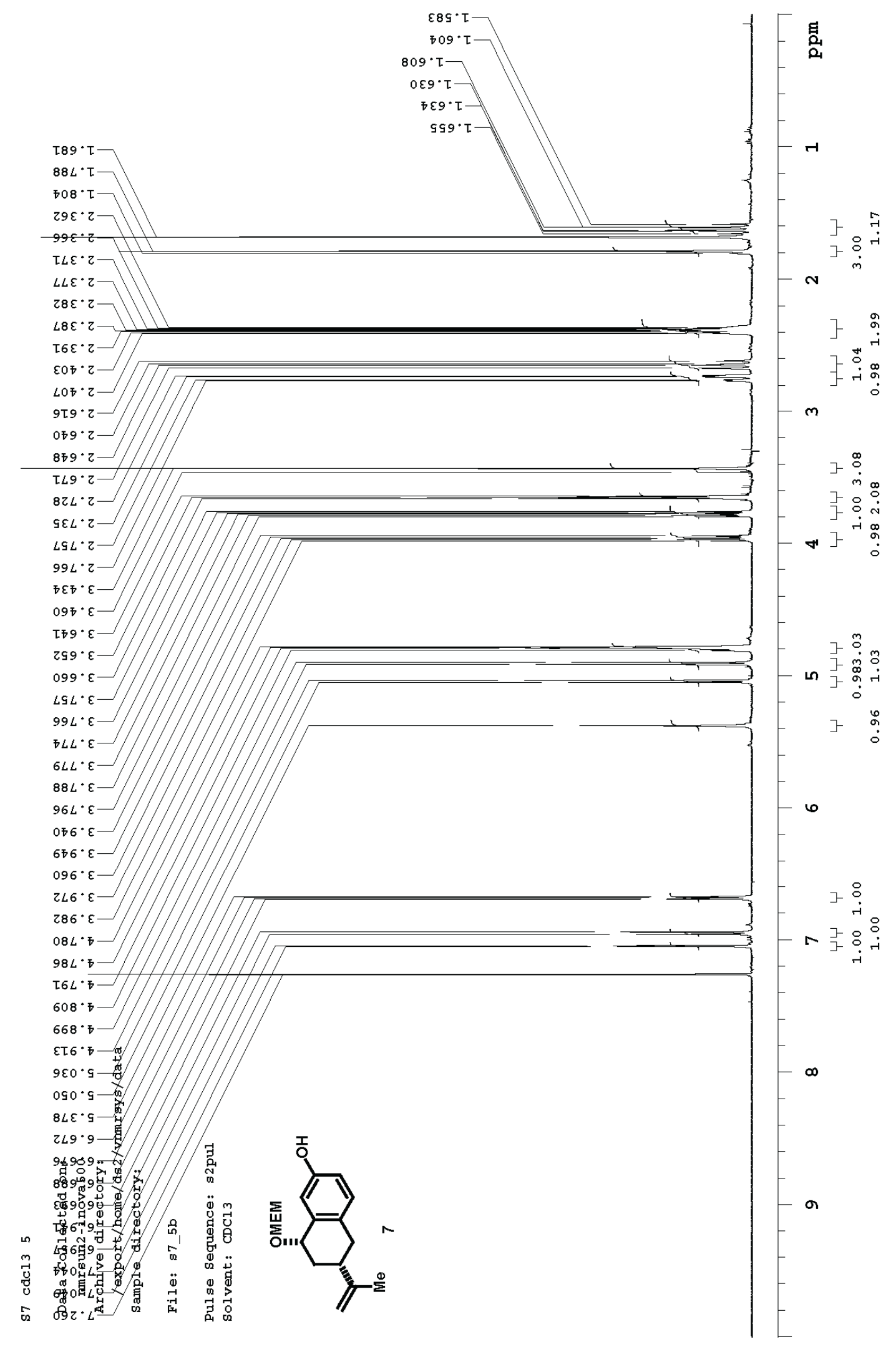




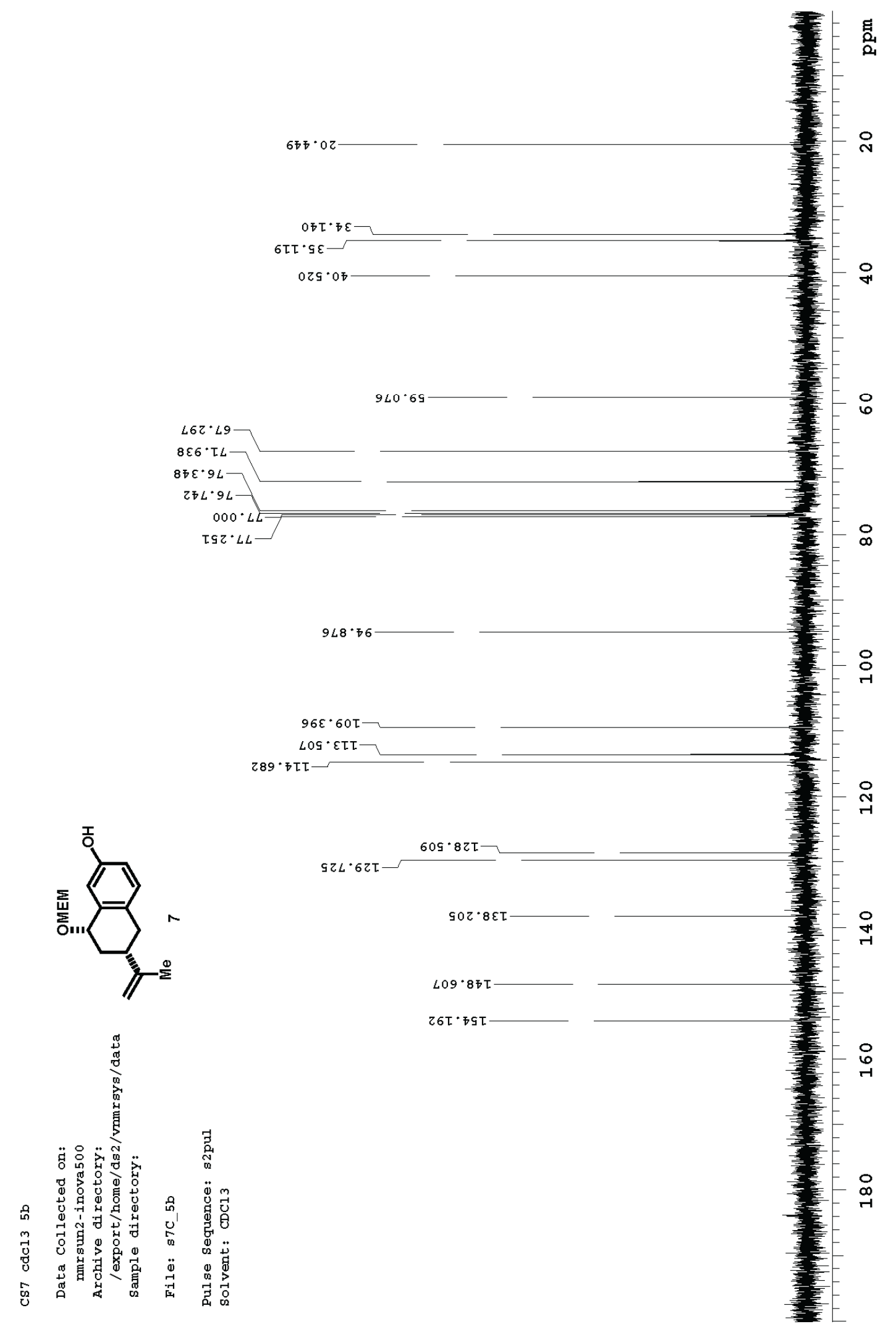




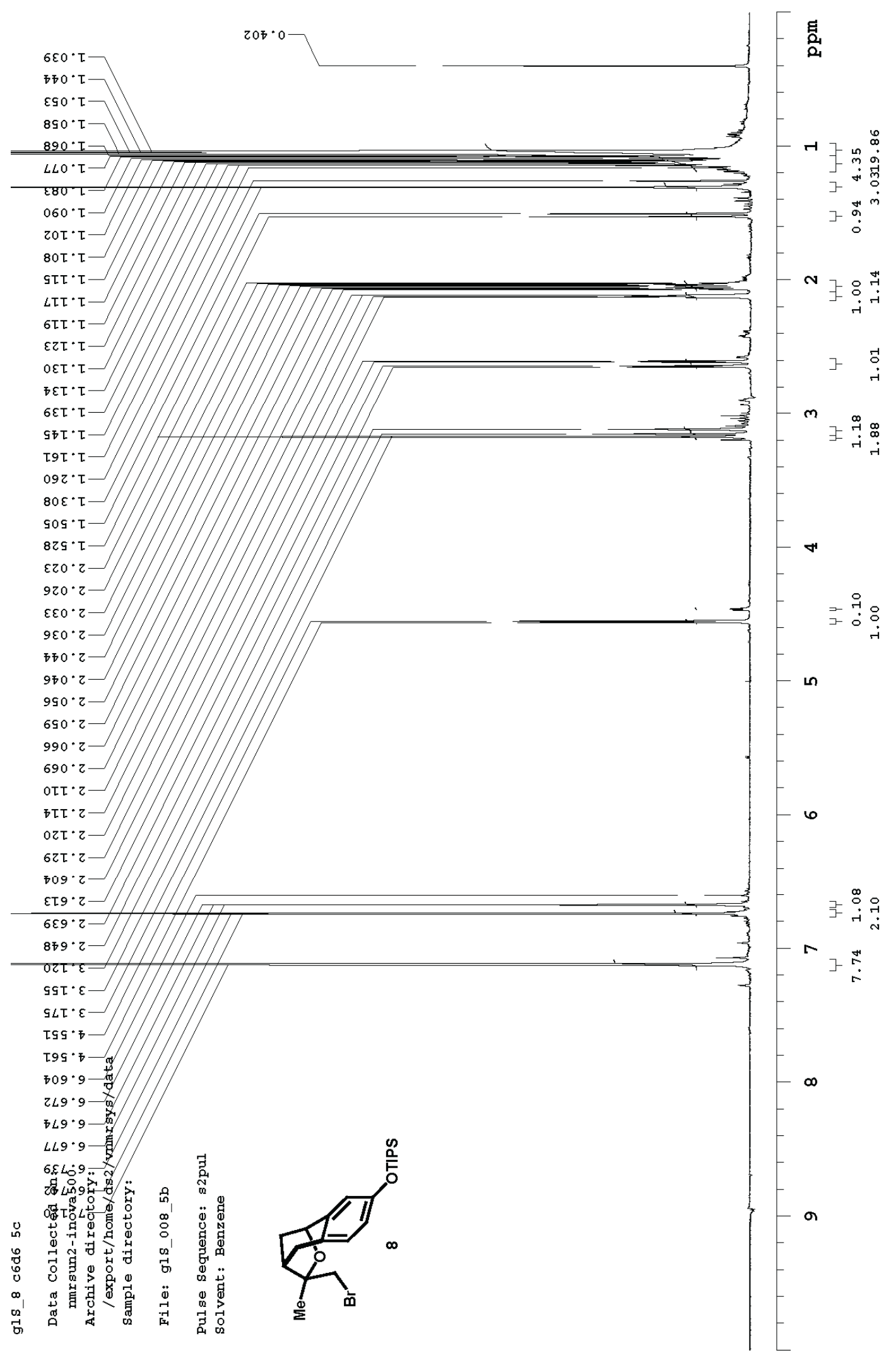




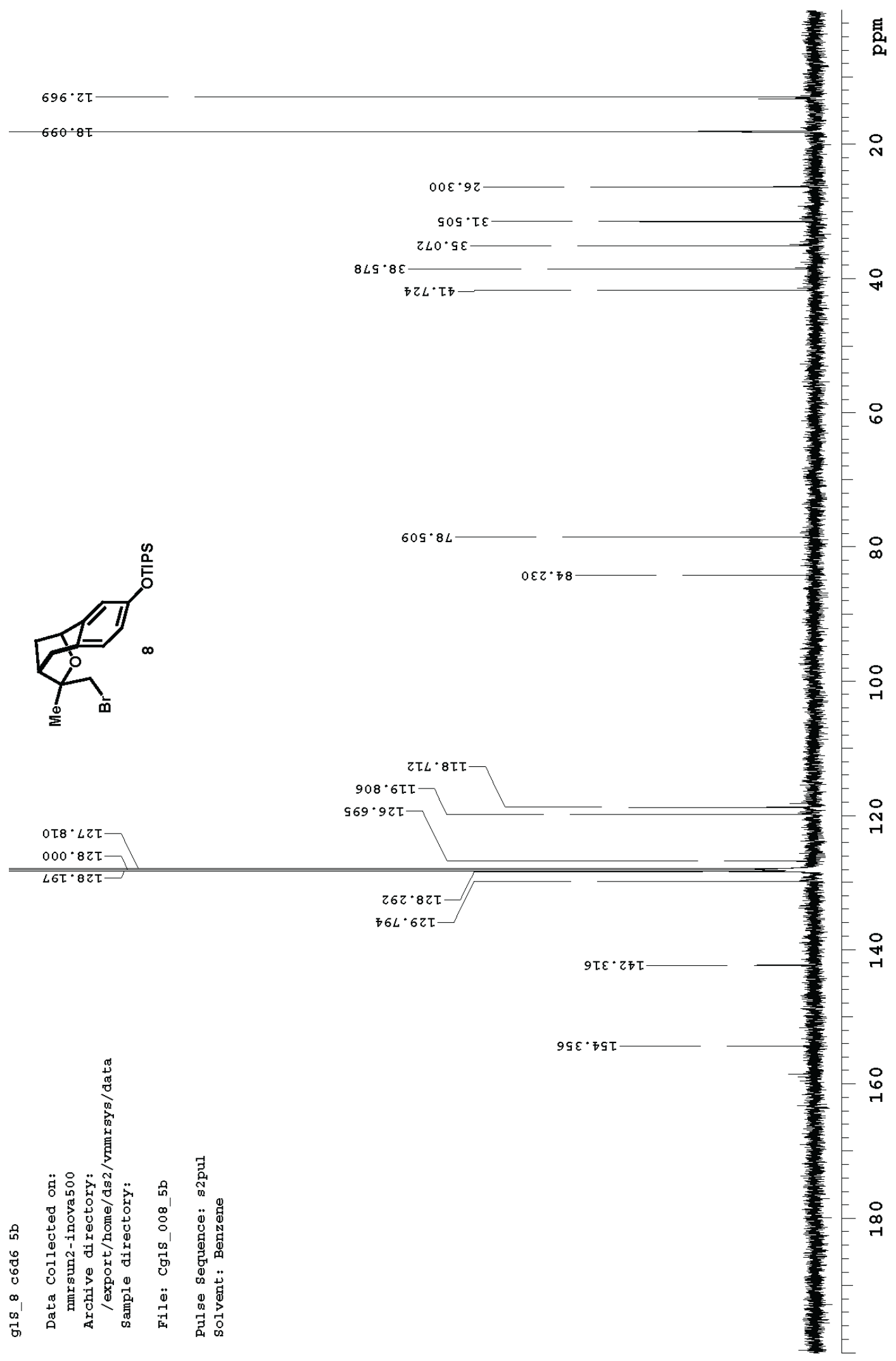




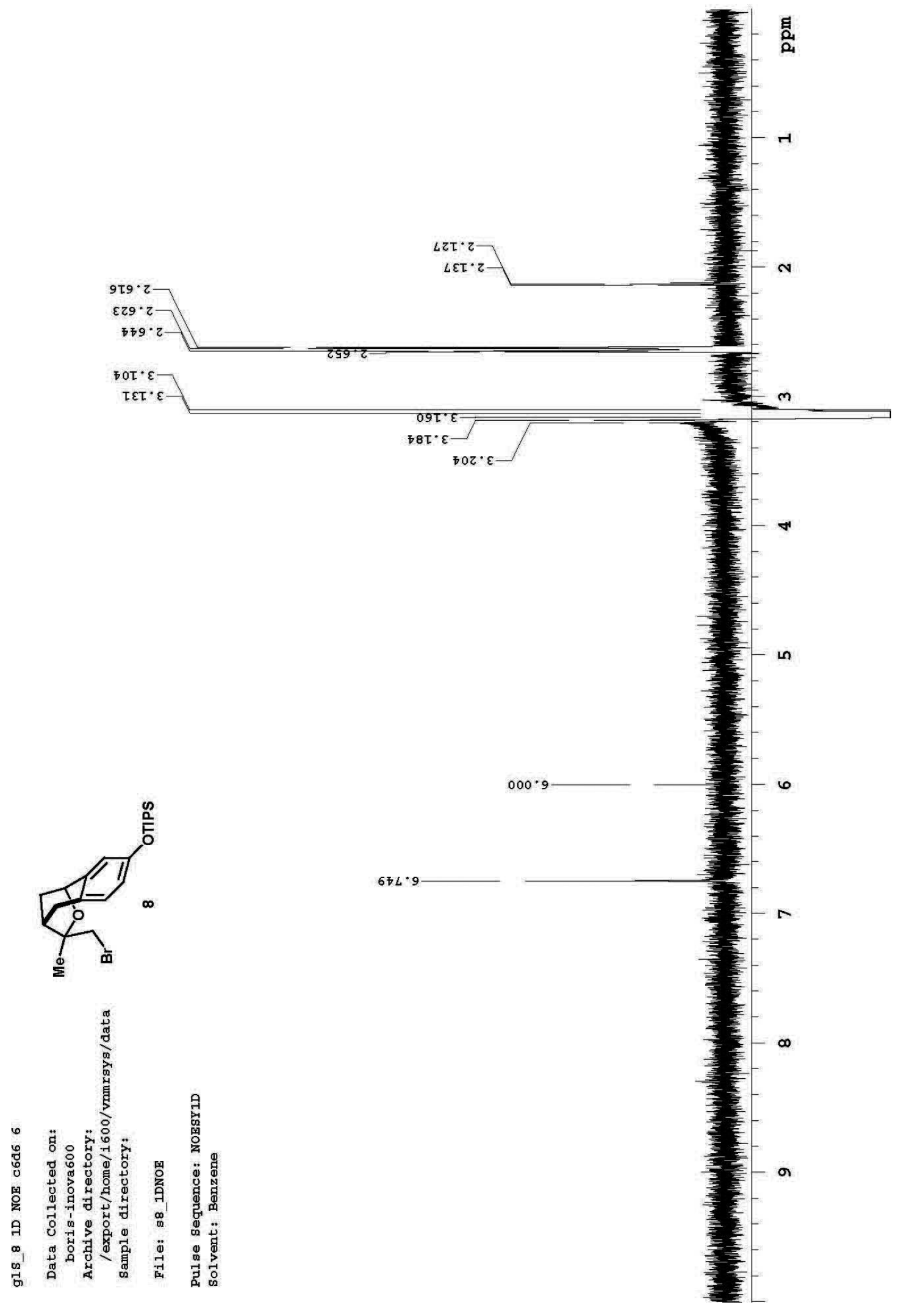




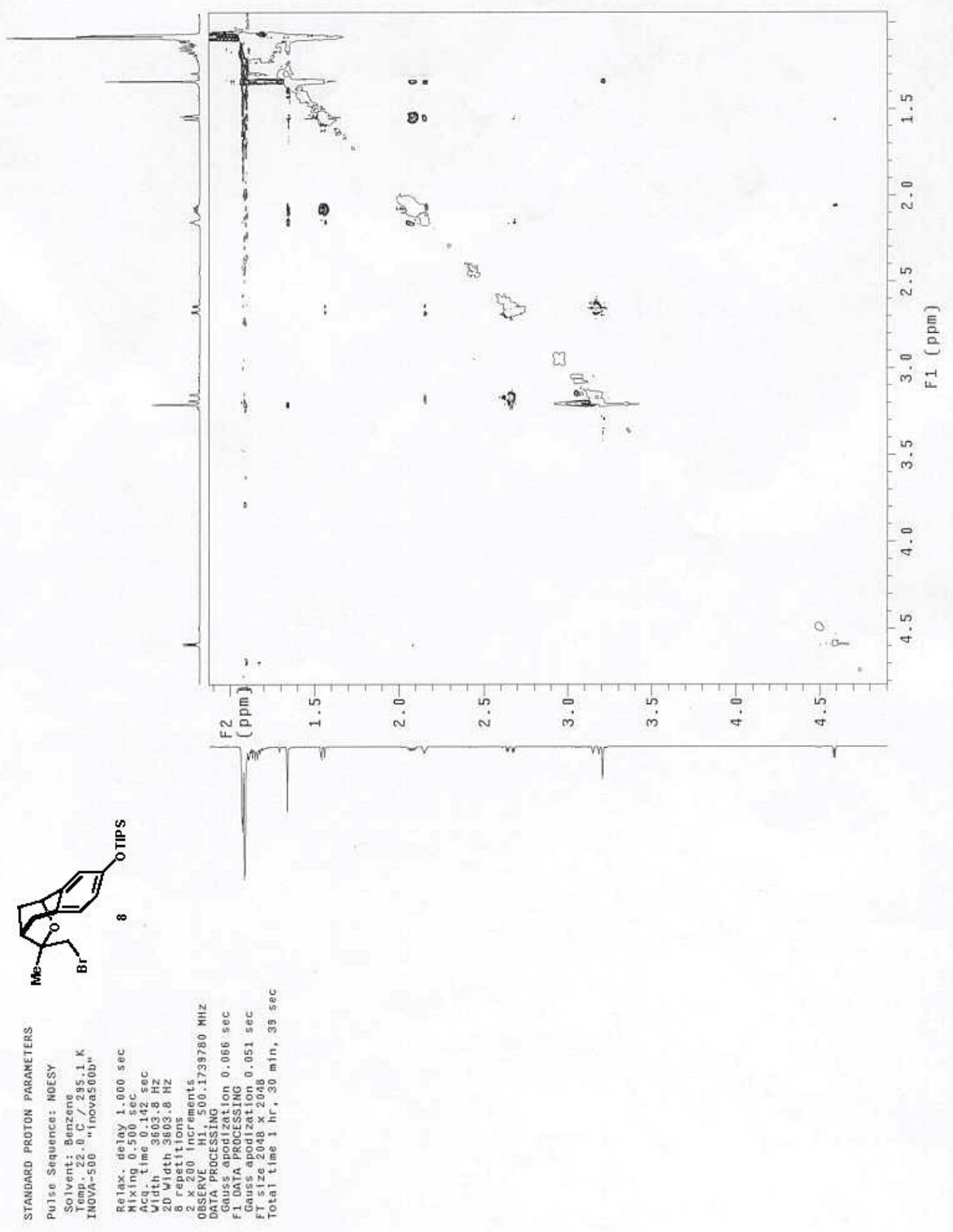




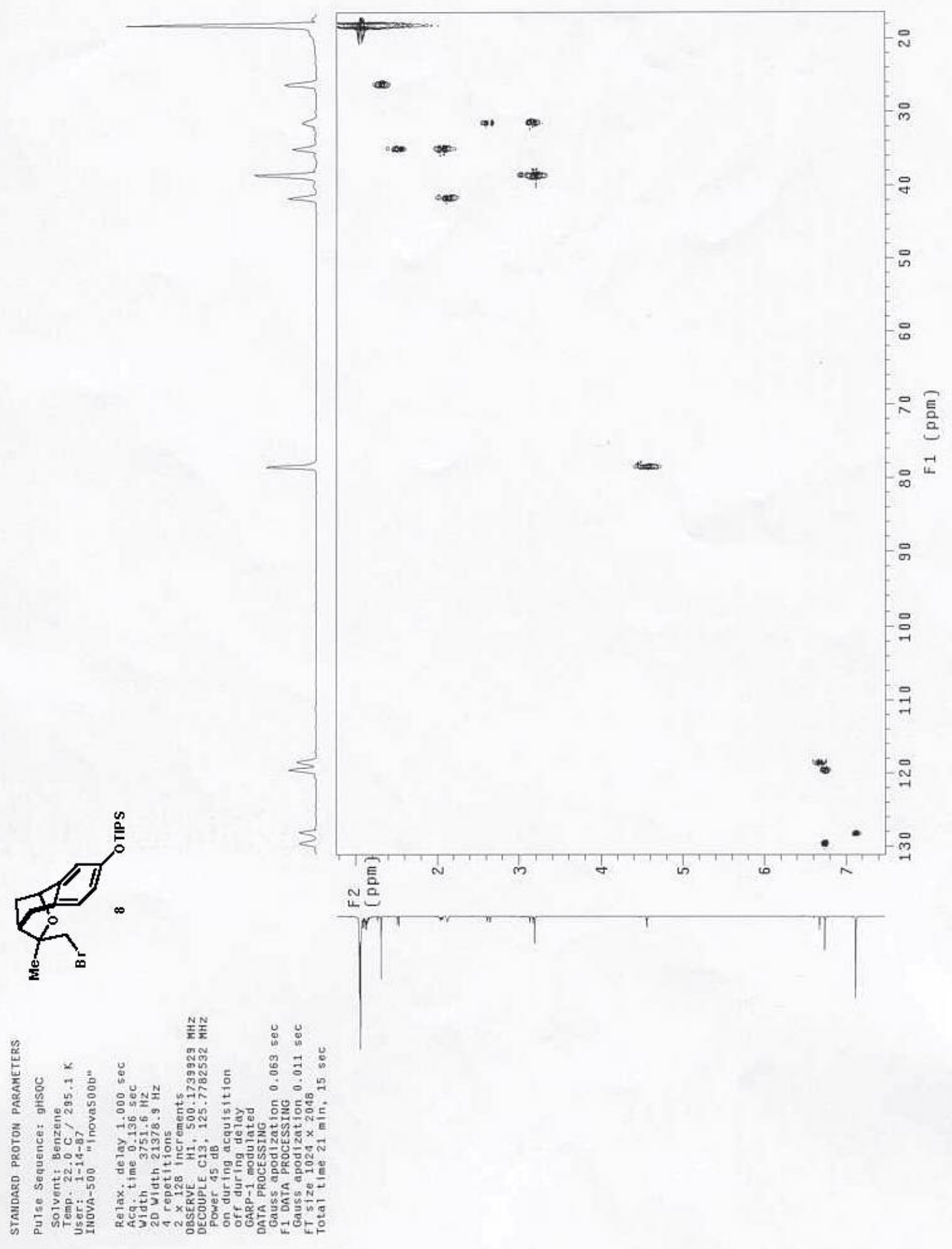




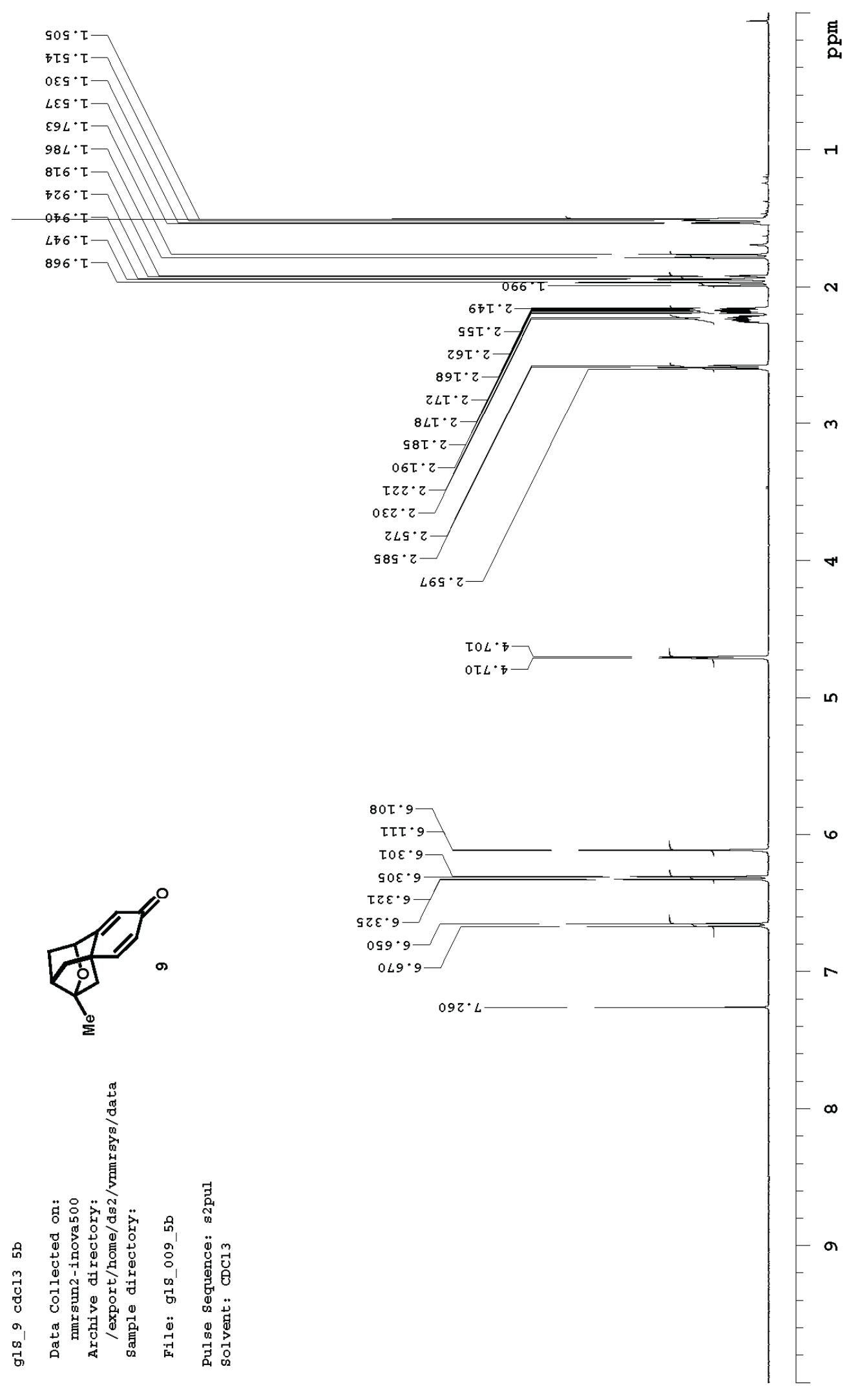




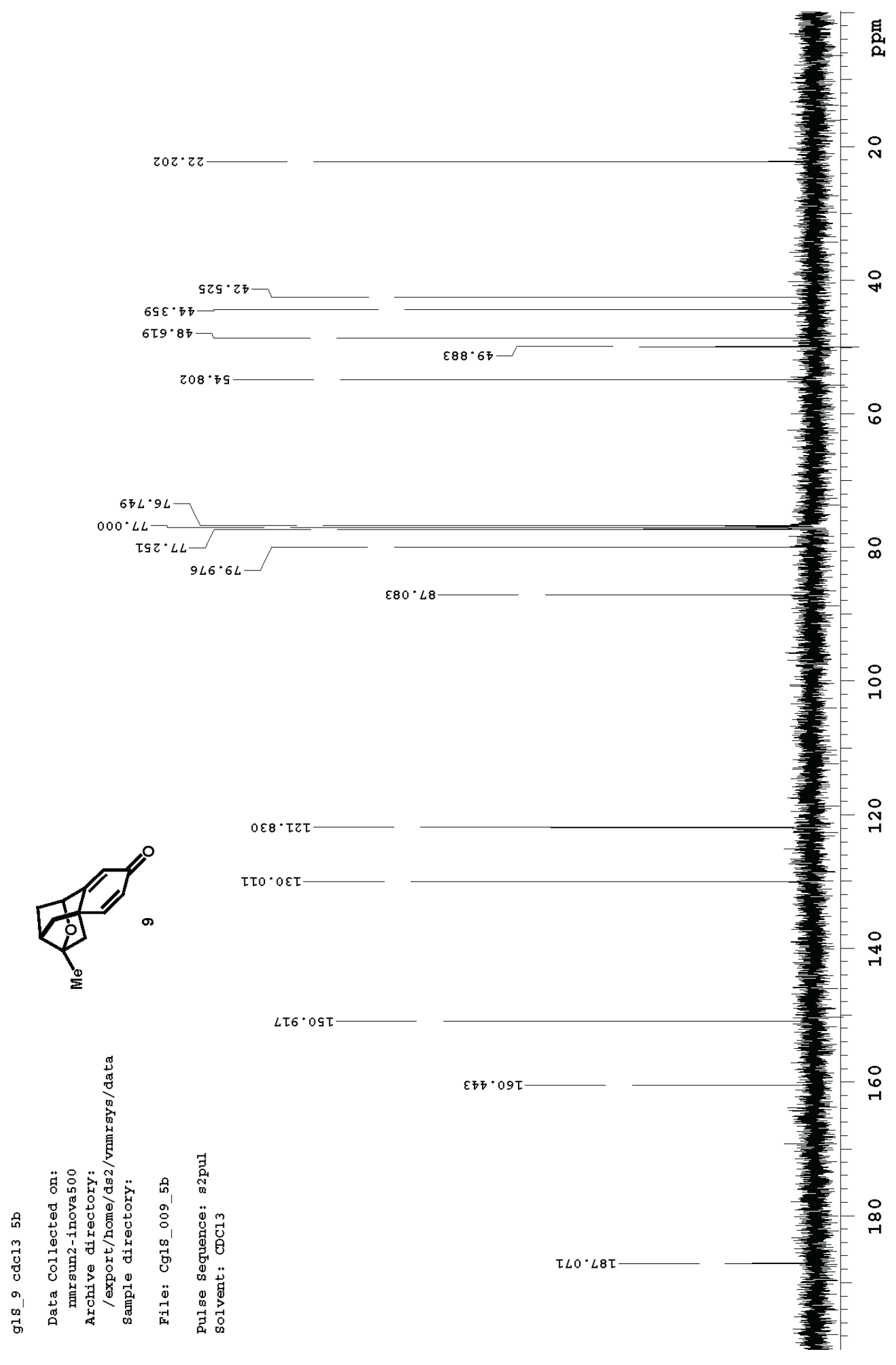




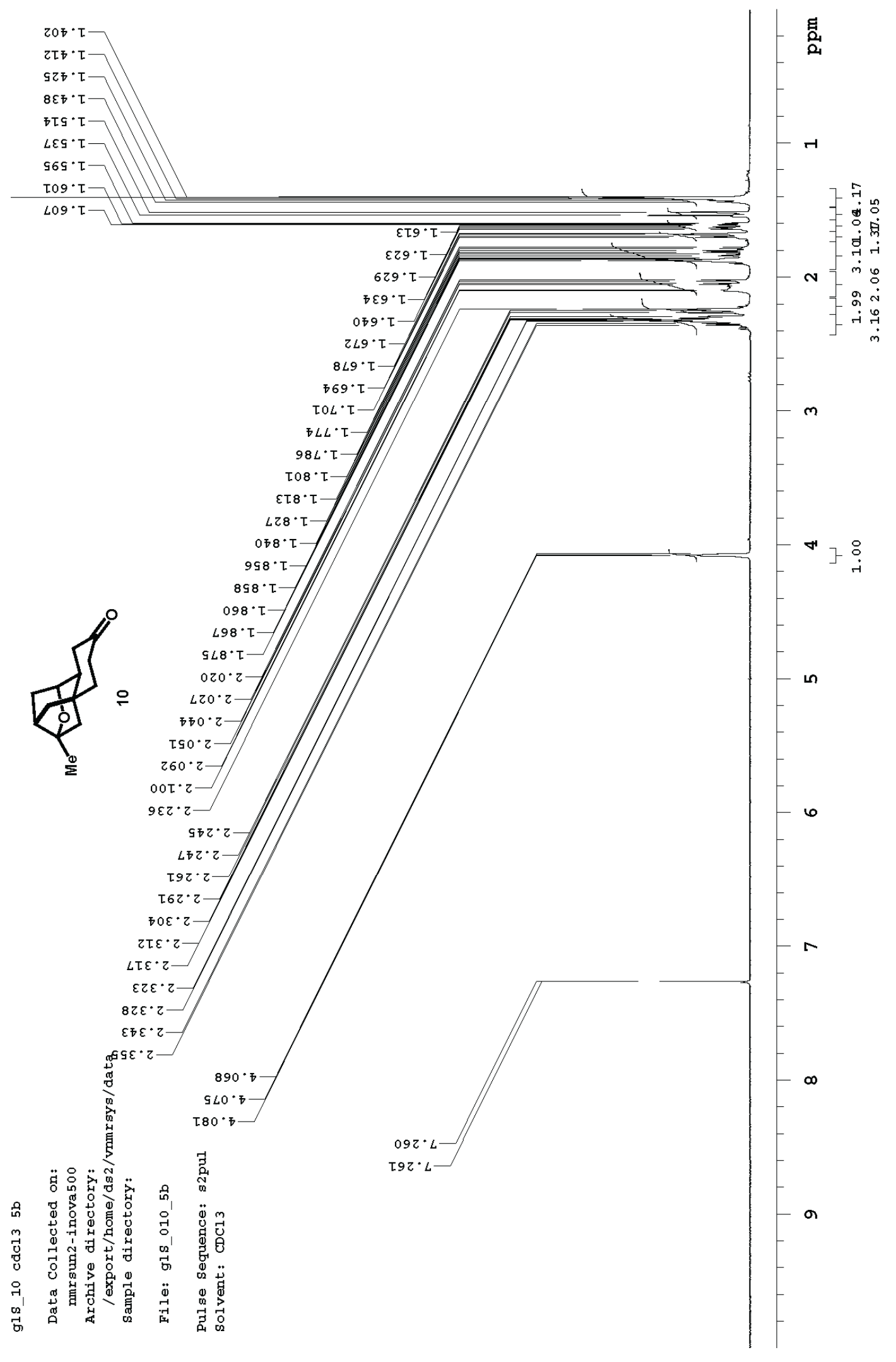




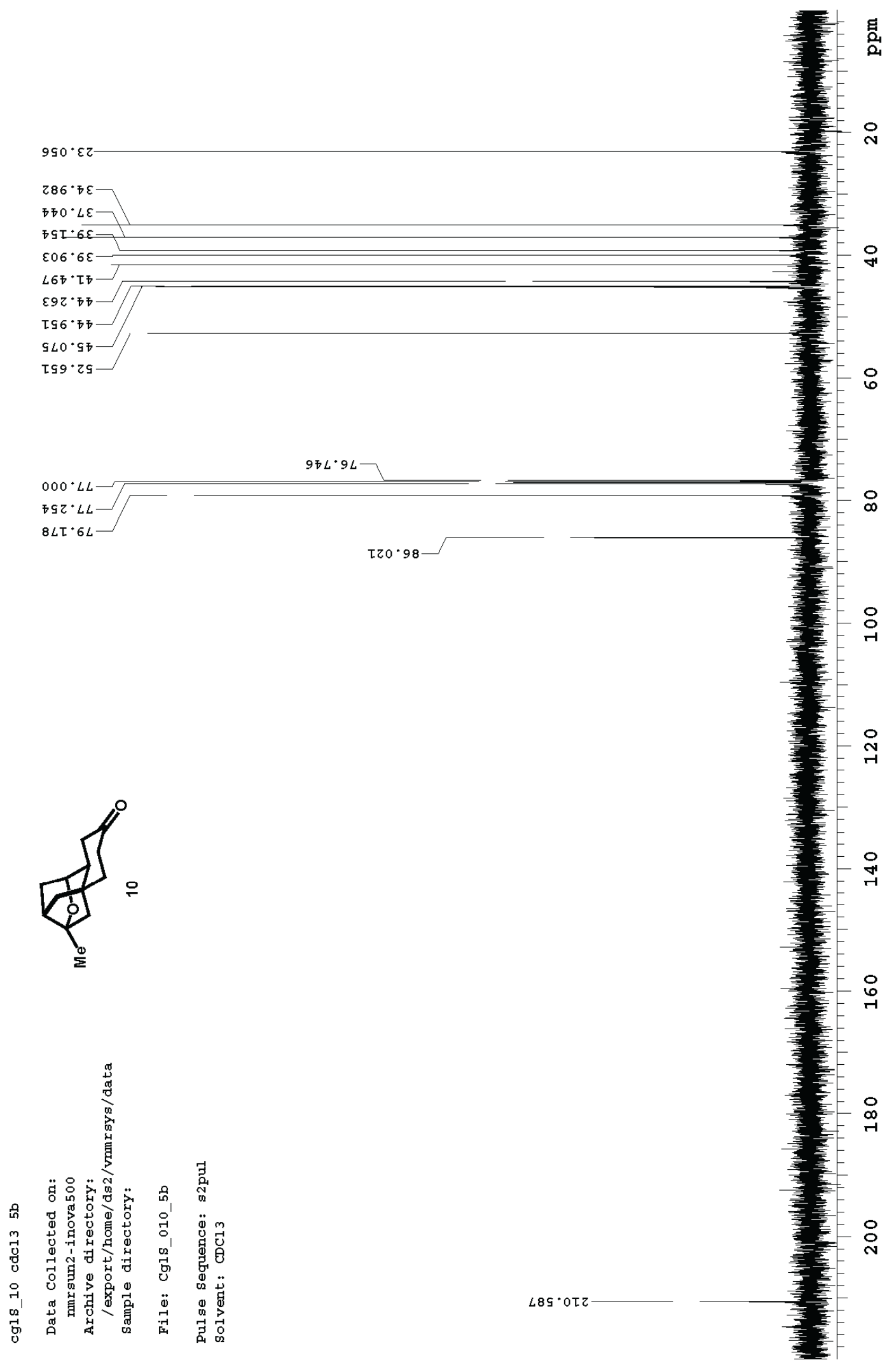




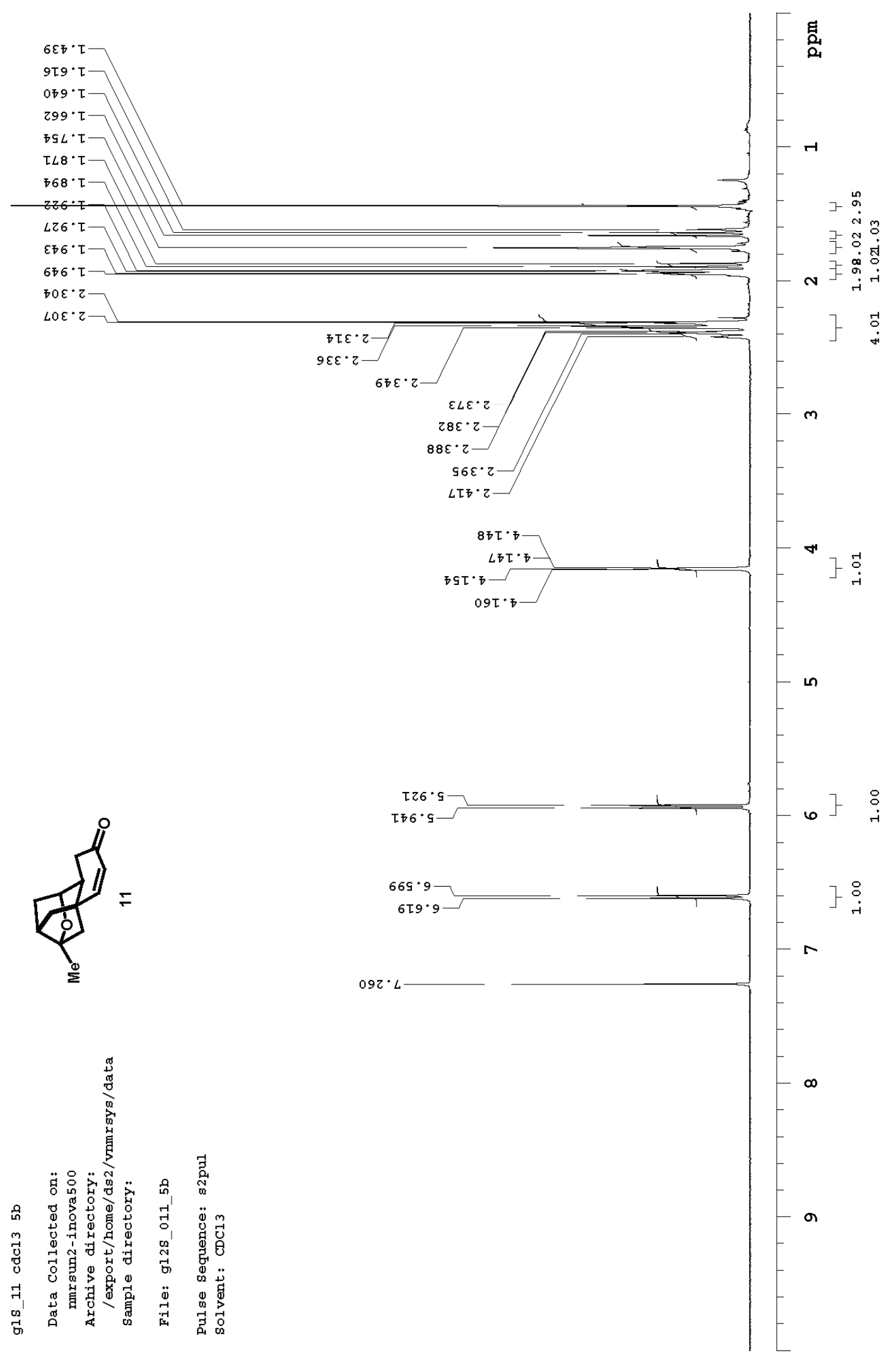




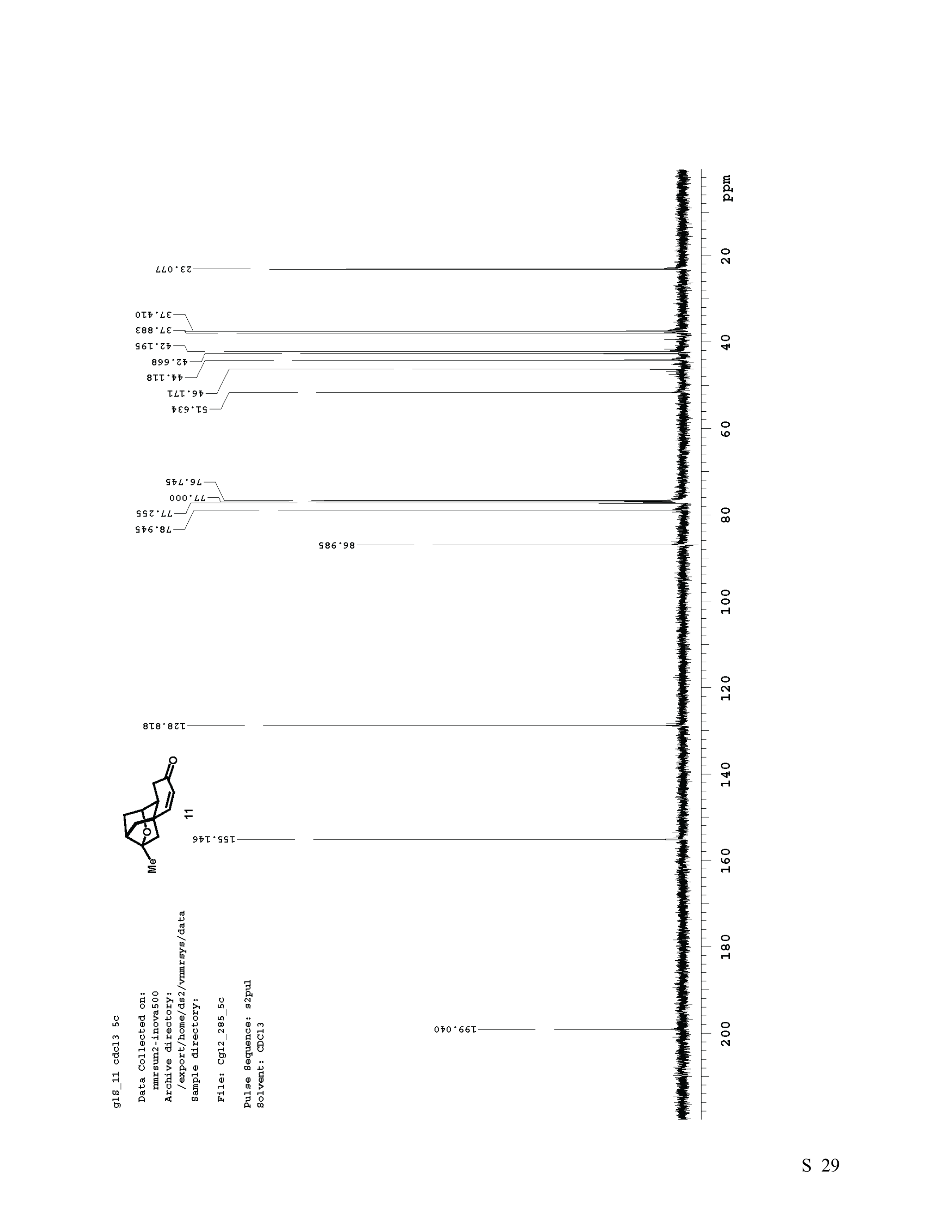



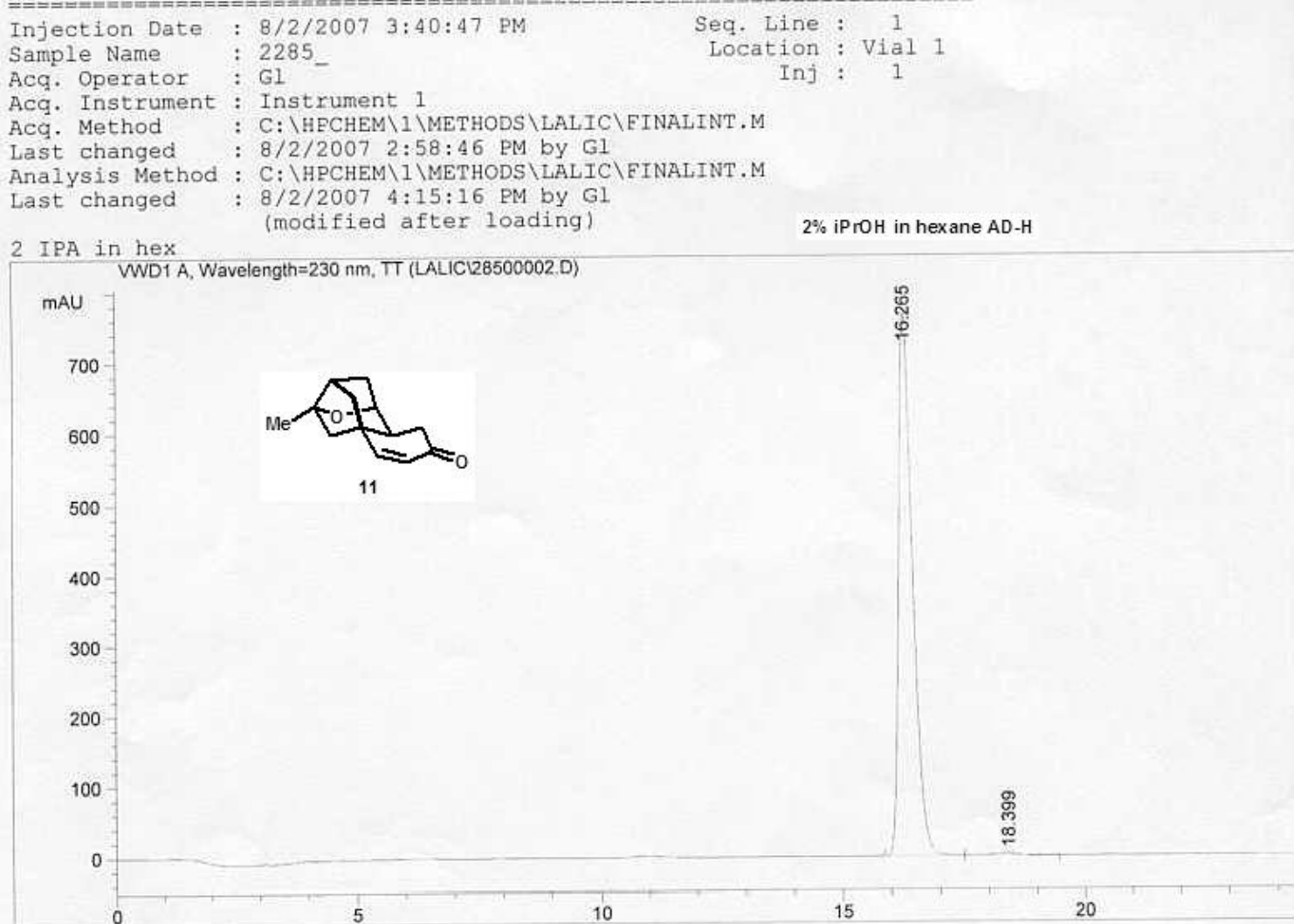

Area Percent Report

$\begin{array}{lcc}\text { Sorted By } & : & \text { Signal } \\ \text { Multiplier } & \vdots & 1.0000 \\ \text { Dilution } & : & 1.0000\end{array}$

Use Multiplier \& Dilution Factor with ISTDS

Signal 1: VWD1 A, Wavelength $=230 \mathrm{~nm}$, TT

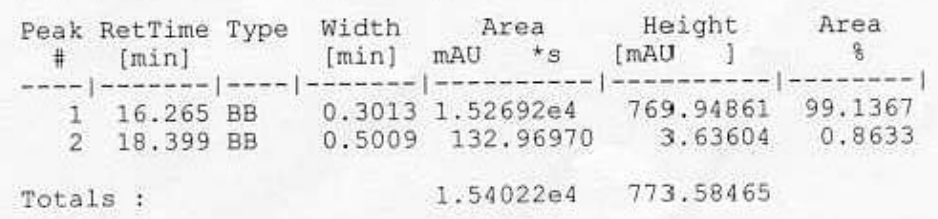

Results obtained with enhanced integrator!

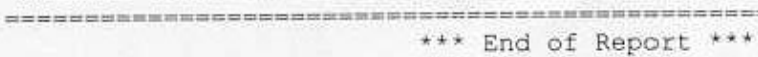




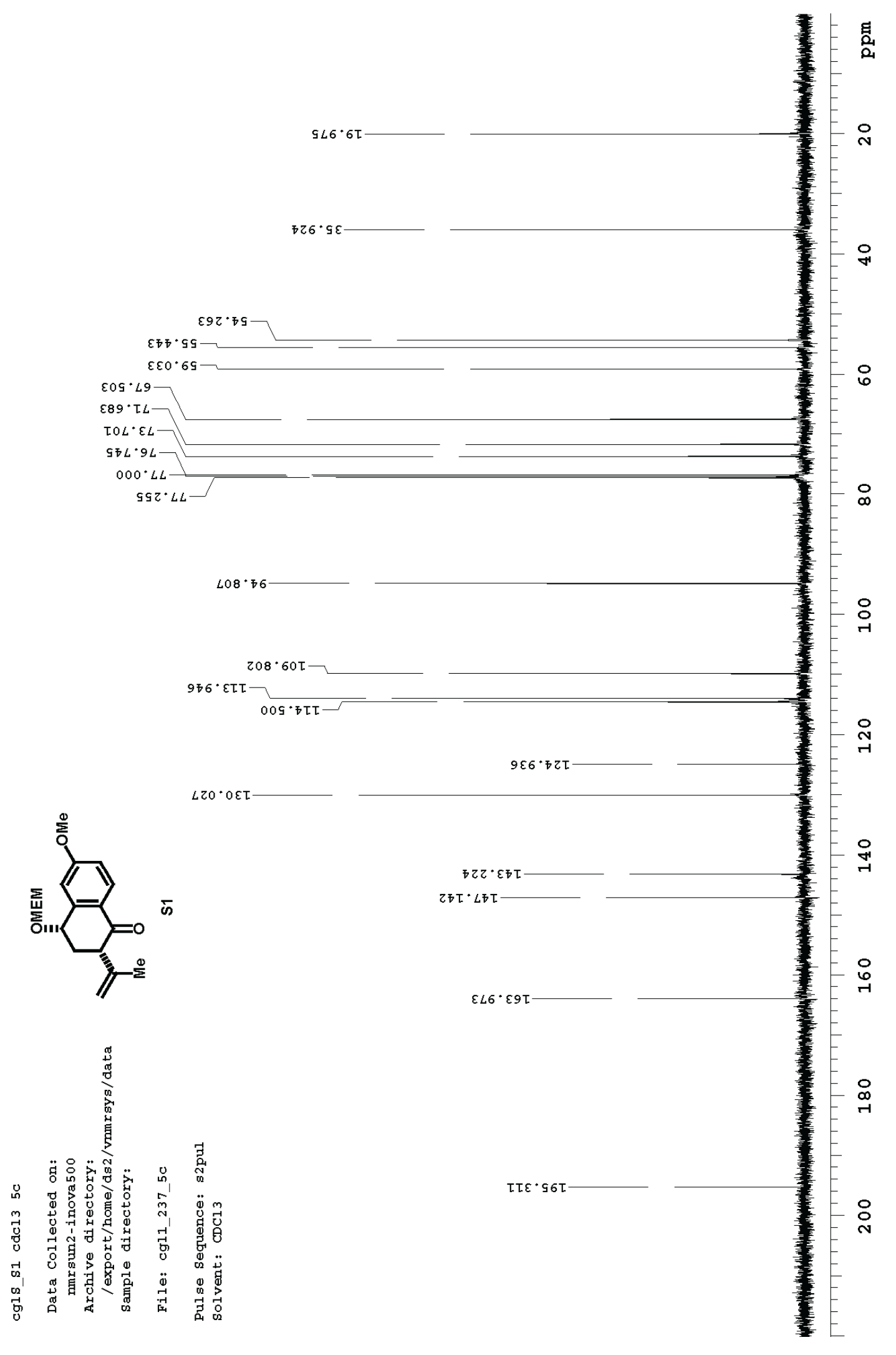




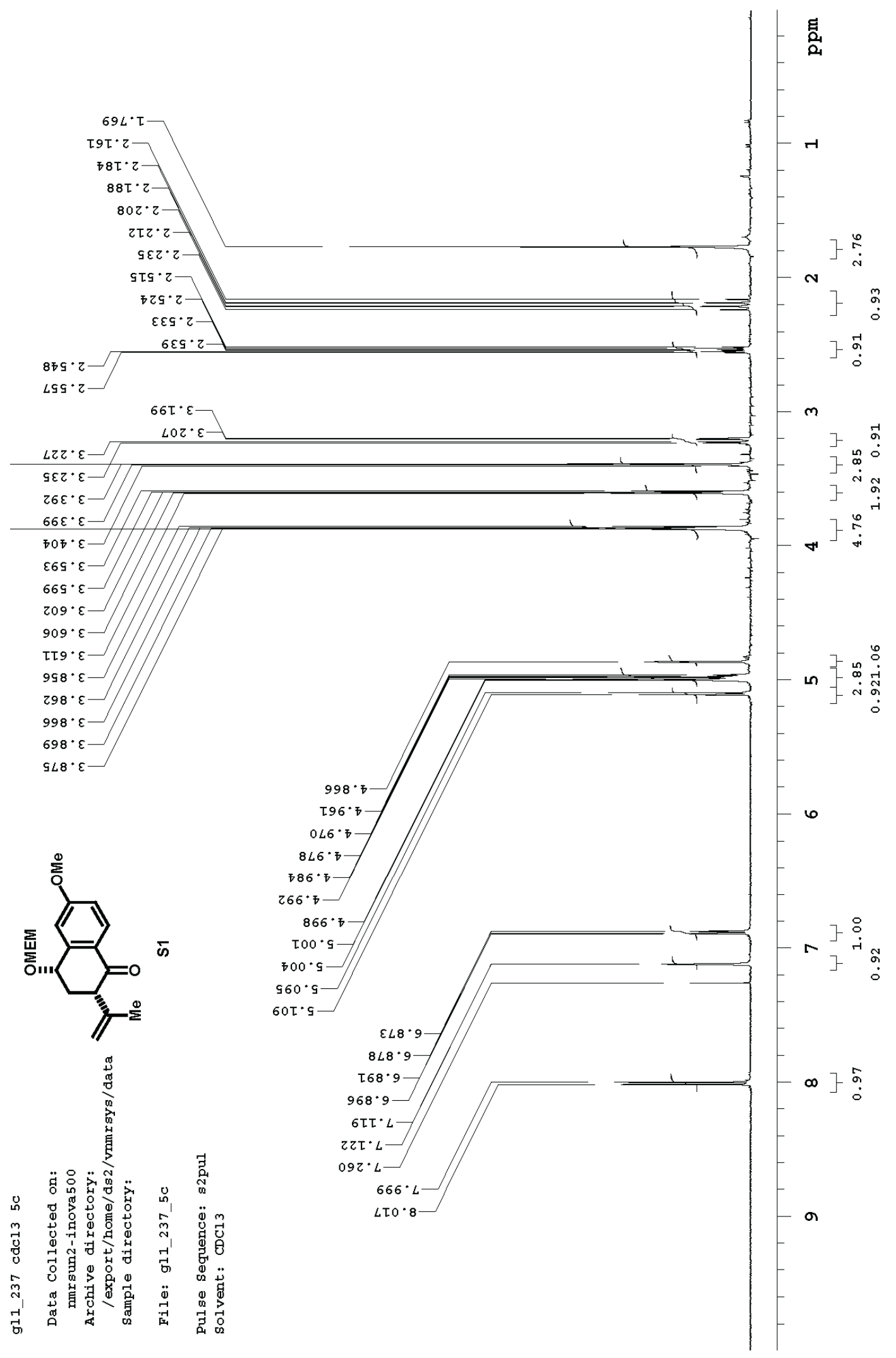

